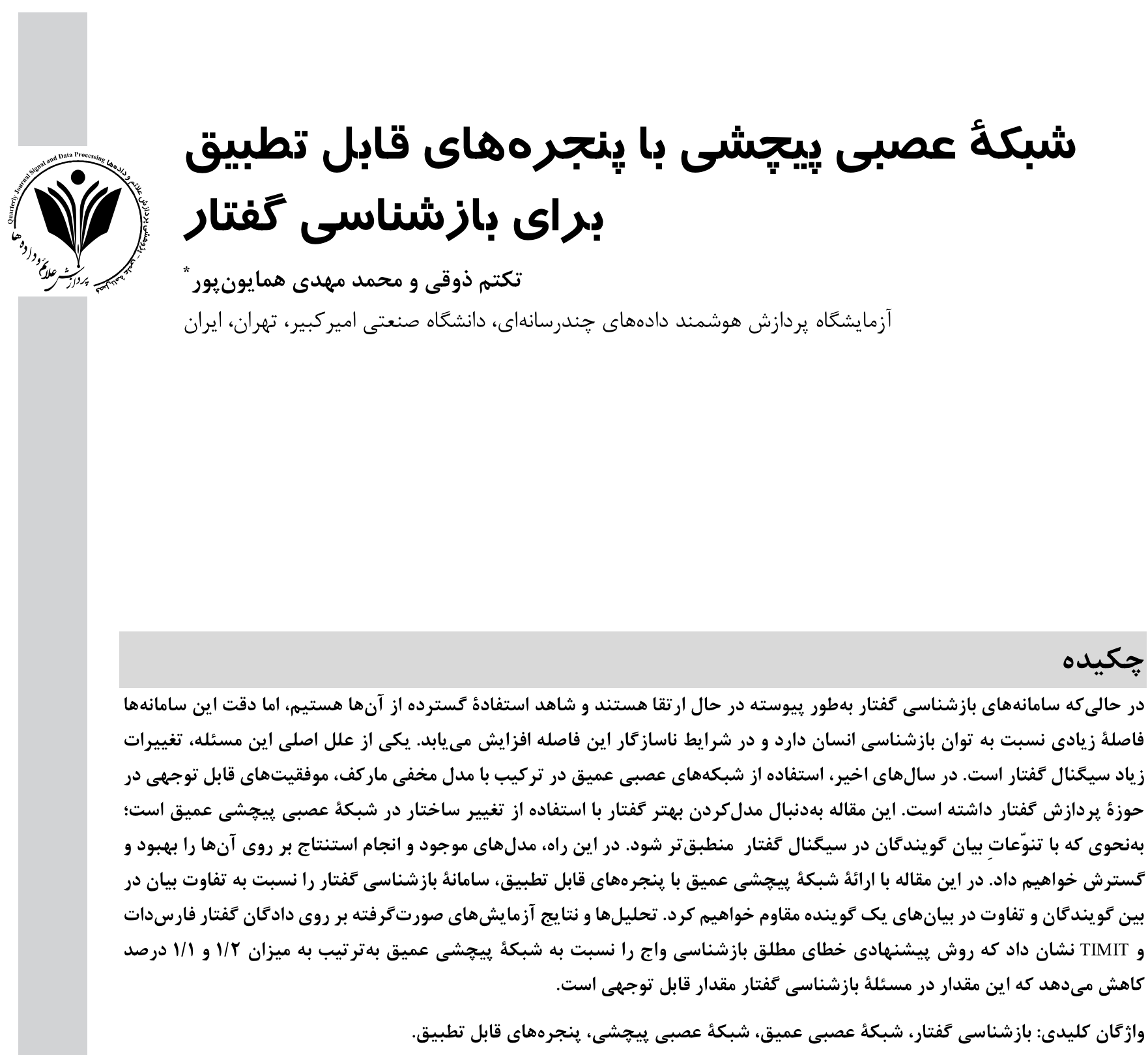

\title{
Adaptive Windows Convolutional Neural Network for Speech Recognition
}

\author{
Toktam Zoughi \& Mohammad Mehdi Homayounpour* \\ Laboratory for Intelligent Multimedia Processing, Department of Computer Engineering \& \\ Information Technology, Amirkabir University of Technology, Tehran, Iran
}

\begin{abstract}
Although, speech recognition systems are widely used and their accuracies are continuously increased, there is a considerable performance gap between their accuracies and human recognition ability. This is partially due to high speaker variations in speech signal. Deep neural networks are among the best tools for acoustic modeling. Recently, using hybrid deep neural network and hidden Markov model (HMM) leads to considerable performance achievement in speech recognition problem because deep networks model complex correlations between features. The main aim of this paper is to achieve a better acoustic modeling by changing the structure of deep Convolutional Neural Network (CNN) in order to adapt speaking variations. In this way, existing models and corresponding inference task have been improved and extended.

Here, we propose adaptive windows convolutional neural network (AWCNN) to analyze joint temporalspectral features variation. AWCNN changes the structure of CNN and estimates the probabilities of HMM states. We propose adaptive windows convolutional neural network in order to make the model more robust against the speech signal variations for both single speaker and among various speakers. This model can better *Corresponding author

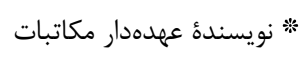


model speech signals. The AWCNN method applies to the speech spectrogram and models time-frequency varieties.

This network handles speaker feature variations, speech signal varieties, and variations in phone duration. The obtained results and analysis on FARSDAT and TIMIT datasets show that, for phone recognition task, the proposed structure achieves $1.2 \%, 1.1 \%$ absolute error reduction with respect to CNN models respectively, which is a considerable improvement in this problem. Based on the results obtained by the conducted experiments, we conclude that the use of speaker information is very beneficial for recognition accuracy.

Keywords: Speech recognition, deep neural network, Convolutional neural network, Adaptive windows convolutional neural network.

ساختارهاى موجود را يذيرفته و بدون تغيير ساختار از طريق ساير روشها كاهش ملايمى در نرخ خطا داشتهاند. اين

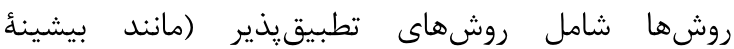

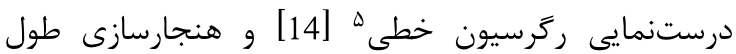

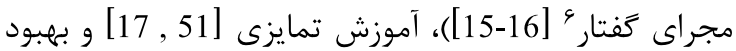
مدل زبانى [18] هستند. در دسترسبودن دادكان خيلى بزرى و توانايى استفاده از كل اين دادكان بسيار سودمند است. بيشتر سامانههاى بازشناسى گفتتار نياز به سامانههاى ارتقايافتهٔ

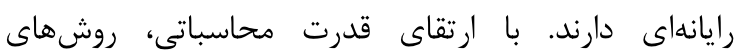
جستجوى قوىترى براى بازشناسى گفتار قابل استفاده

سؤال اساسى در مسائل بازشناسى گفتتار : جكونكى

مدل كردن صوت براى استخراج ويزگى هاى صوتى و درنهايت برجسبزنى مناسب فريمهاى كفتارى است. در سال هاى اخير، شبكههاى عصبى عميق در تركيب با مدل مخفى ماركف، مدلى موفق براى حل مسائل در حوزه يردازش كفتار به ارمغان

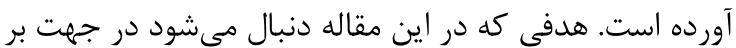
طرفكردن يكى از خالشهاى اساسى در مسائل بازشناسى

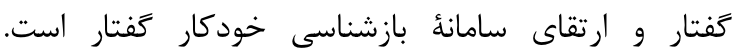
ويثزى هاى متفاوت مجارى كفتارى گويند

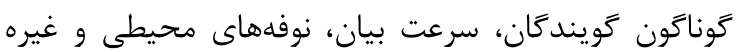
باعث تغييرات زيادى در سيخنال كفتارى انسان مىشون،

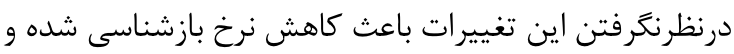

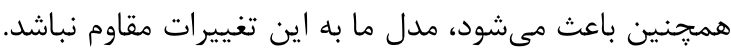

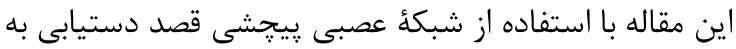
مدلى مقاوم به اين نوع تنوعات را دارد.

در بخش بعد، روشهاى بيشين مرتبط با مقاله را در

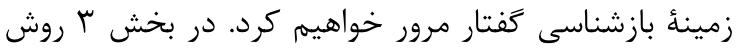
ييشنهادى ما به نام AWCNN معرفى و توصيف و در بخش

${ }^{5}$ Maximum Likelihood Linear Regression (MLLR)

${ }^{6}$ Vocal Tract Length Normalization (VTLN)

${ }^{7}$ Adaptive windows convolutional neural network (AWCNN)

\section{- مقدمه}

هدف بازشناسى خودكار زفتار، دريافت ₹فتار ضبطشده

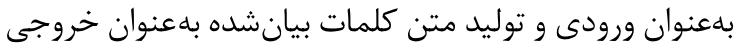
است. كاربردهاى فراوان و روبهرشدى در وردئ زمينهُ بازشناسى

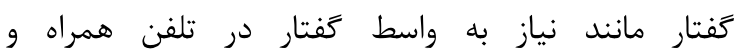
برجسب گذارى دادگان كَتارى و ويدئويى براى جستجوى آنها وجود دارد. براى تمام اين كاربردها نيازمند سامانههاى

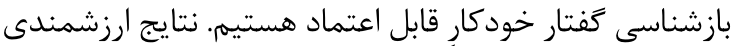

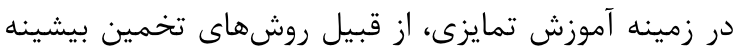

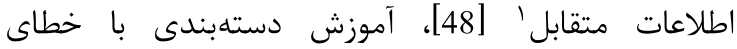

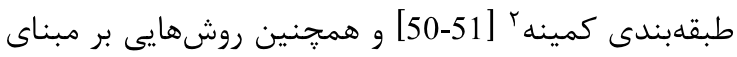

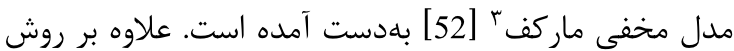
هاى ذكرشده، روشهاى جديدى براى مدلى ملردن سامانه صوتى مانند ميدانهاى تصادفى شرطى (CRF)

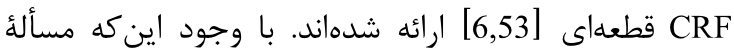
بازشناسى كفتار بيش از ينجاه سال است با وسعت زياد مطالعه

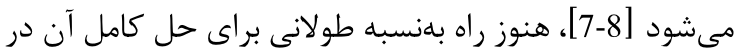
ييش است. همراكنون فناورى بازشناسى خودكار كفتار ، بهطور

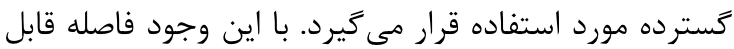
تأملى بلخصوص در شرايط ناساحار بين دقت انسان و ماشين

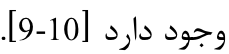

\section{|-1- نياز براى ارائهُ مدل بهتر}

بر خلاف ييشرفتهاى قابل توجهاى كه در دهdهاى اخير در

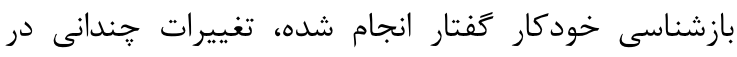

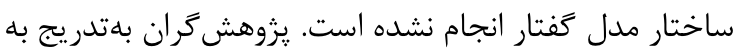

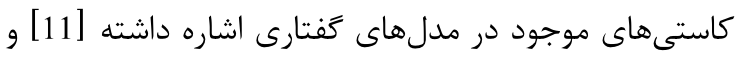

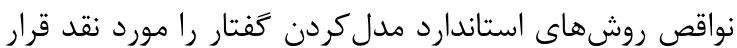
دادهاند [12-13]. بيشتر روشهاى رونتاندار عملى در بازشناسى كفتار

${ }^{1}$ Maximum Mutual Information (MMI)

${ }^{2}$ Minimum Classification Error (MCE)

${ }^{3}$ Hidden Markov Model (HMM)

${ }^{4}$ Conditional Random Fields (CRF) 


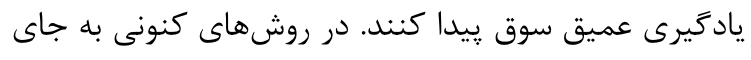

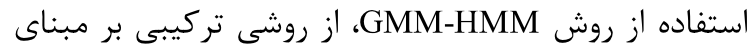

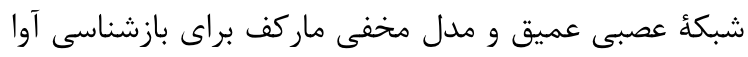
استفاده شده است [21-19].

در اين روش به جاى مدل مخلوط كاوسى از شبكأ عصبى عميق كه بهصورت تمايزى آموزش ديده است، استفاده

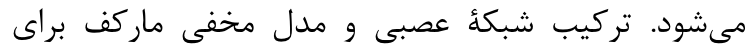

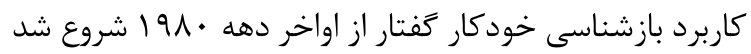

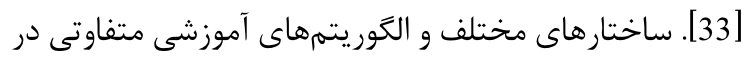

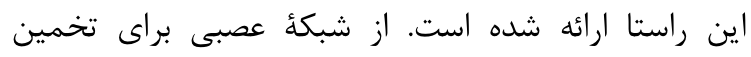
احتمالات يسين حالات مدل مخفى ماركف استفاده شده

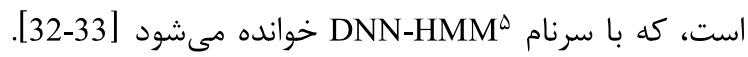
در اين مدل، خروجى شبكه عصبى براى تخمين احتمال

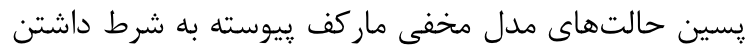
مشاهدات آكوستيكى، آموزش مىبيند.

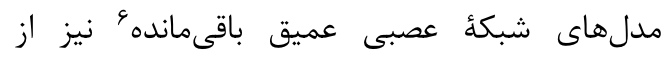

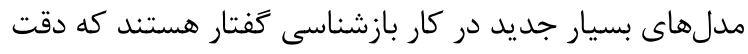

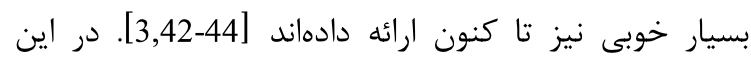
مدلها، خروجى شبكة عصبى باقىمانده براى تخمين احتمال

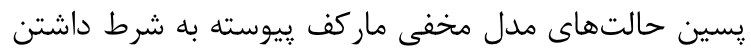

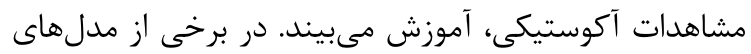

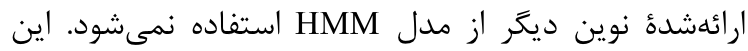

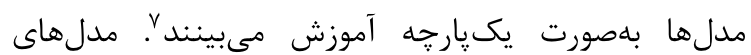

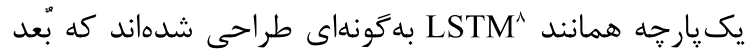

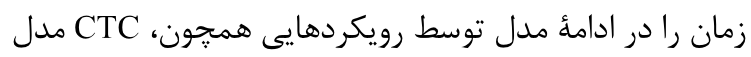
خواهند كرد و درنتيجه خون خطاى كل ردان سامانه يكيارجه

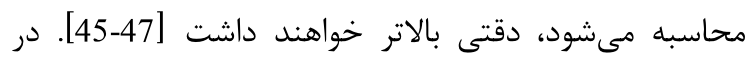

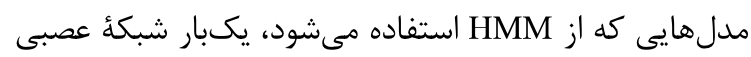

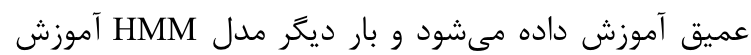

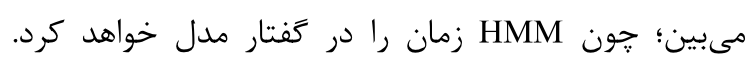

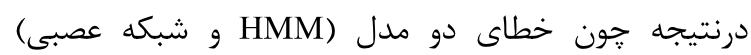
متفاوت محاسبه مىشود و بنابراين اكر مدل نخست دون خدون

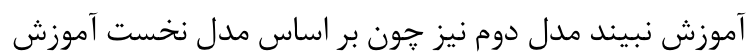

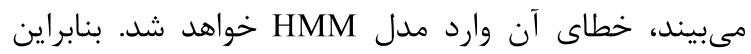

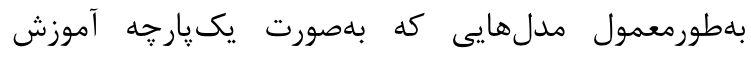

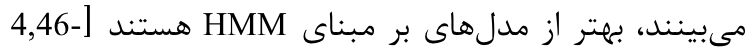

. [47

${ }^{5}$ Deep Neural Network Hidden Markov Network (DNNHMM)

${ }^{6}$ Deep Residual Learning

${ }^{7}$ End to End

${ }^{8}$ Long Short-Term Memory (LSTM)
F انتايج ارزيابى و مقايسٔ روش بيشنهادى با ساير روشهاى

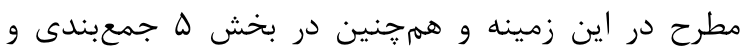
نتيجه كيرى ارائه مىشود.

\section{r- مرور: روشهاى مدلكردن صوت در بازشناسى كَفتار}

در دو دهأ اخير مدلهاى مخفى ماركف از روشهاى باى غالب

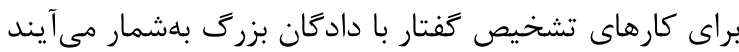

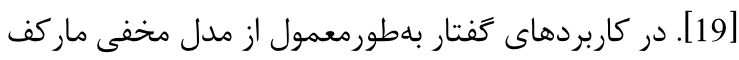

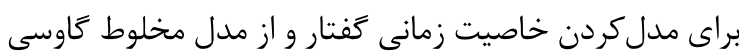

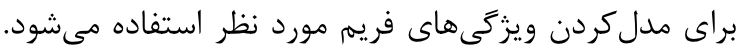

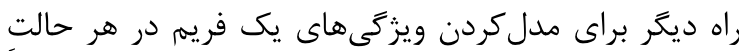
مدل مخفى ماركف، استفاده از شبكه عصبى عميق است. اين

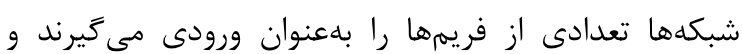

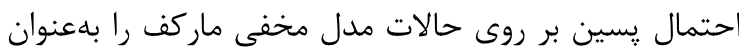

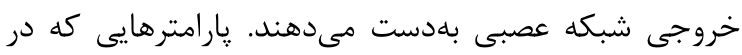

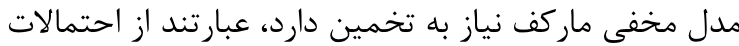

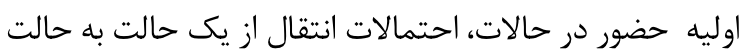

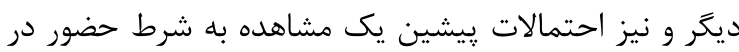

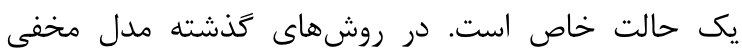
ماركف، احتمال مشاهدات توسط مدل مخلوط گأوسى تخمين

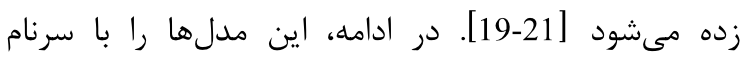
نشان مى دهيم. توانايى اين مدل ها بهخاطر

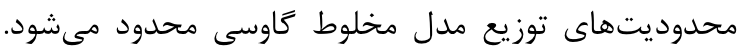

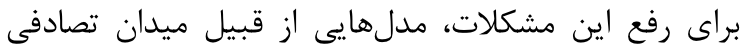

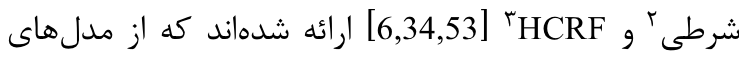
لكًاريتم خطى "ُ براى جايكزينى GMM-HMM استفاده مى كند. نتايج بهدست آمده نشان داده است، كارئي ائي اين روش

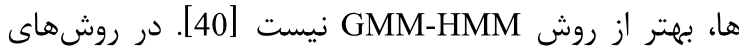

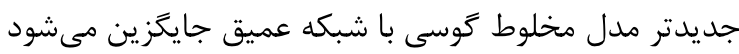

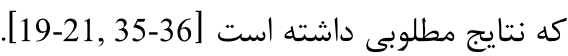

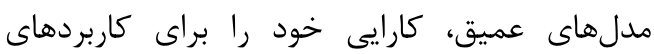

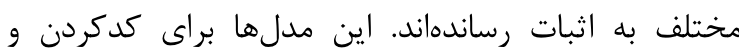
دستهبندى دادهاي كَفتار، متن و تصوير كارائى خوبى نشان اندان

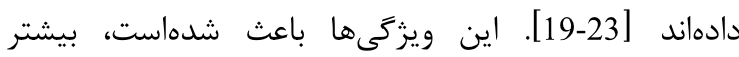

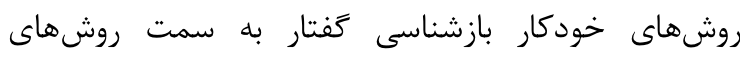

${ }^{1}$ Gaussian Mixture Model Hidden Markov Model (GMMHMM)

${ }^{2}$ Conditional Random Fields (CRF)

${ }^{3}$ Hidden Conditional Random Fields (HCRF)

${ }^{4}$ Log-linear models 


\section{r-Y - شبكة عصبى ييجشى}

شبكة عصبى يبحشى همانند شبكأ عصبى، يك لائُ ورودى و

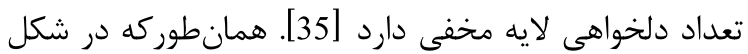

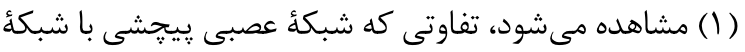

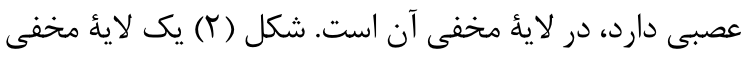

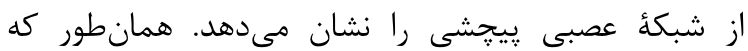

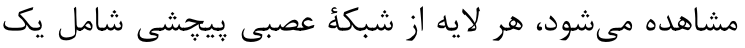

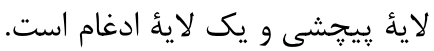

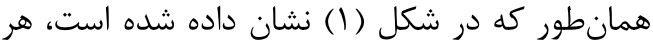

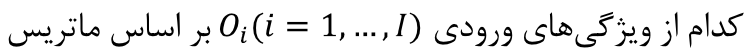
وزنها (J (, .,

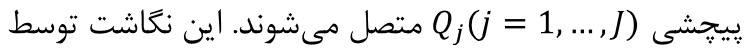

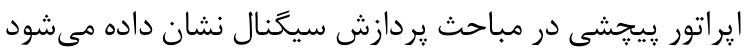

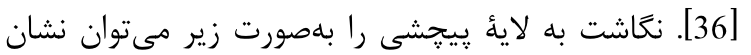

$$
\begin{aligned}
& q_{j, m}= \\
& \sigma\left(\sum_{i=1}^{I} \sum_{n=1}^{F} o_{i, n+m-1} w_{i, j, n}+w_{0, j}\right), \\
& (j=1, \ldots, J)
\end{aligned}
$$

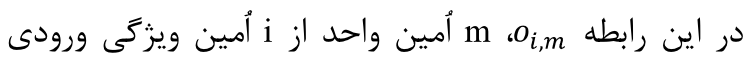
است. F اندازه فيلتر است، كه تعيينكنيندة تعداد باندهائ

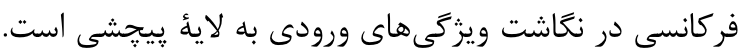

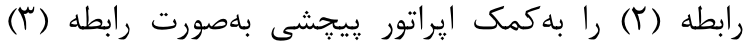

$$
\begin{aligned}
& Q_{j}=\sigma\left(\sum_{i=1}^{I} O_{i} * w_{i, j}\right) \\
& (j=1, \ldots, J)
\end{aligned}
$$

تعداد دسته نغاشتهاى ويزّى در لائُ يِيجشى بلهور مستقيم، تعداد ماتريس هاى وزن محلى مورد استفاده در

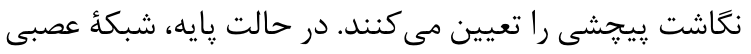
״يجشى ينجرهاى مستطيلشكل، بهطول تعداد فريمهاى

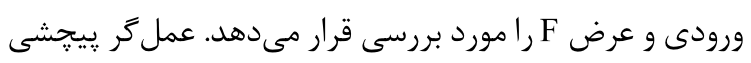
بهنسبت F، نكاشتى با ابعاد بايينتر توليد مى كند.

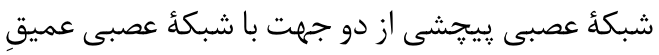

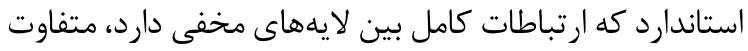

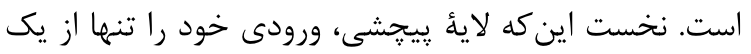
فضاى محلى دريافت مى كند. بدين معنى كه هر وردئ واحد،

\footnotetext{
${ }^{4}$ Convolutional Deep Neural Network Hidden Markov Network (CNN-HMM)
}

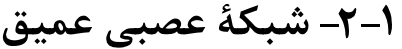

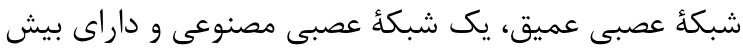

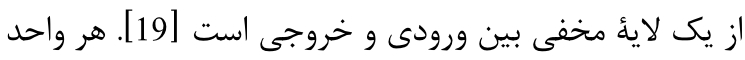

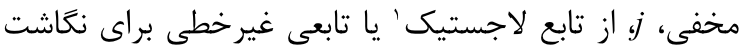

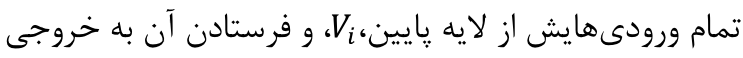
كه يك مقدار عددى است، استفاده مى كند:

$$
h_{j}=\sigma\left(\sum_{i} v_{i} W_{i, j}+c_{j}\right)
$$

در شبكههاى عصبى عميق احتمال بيشبرازش' وجود دارد

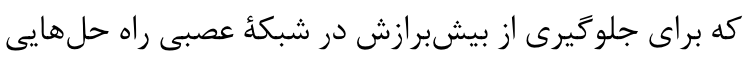
متنوعى وجود دارد [37]. شبكة عصبى با تعداد زيادى لايه دريه داراى يارامترهاى زيادى است، كه تشكيل يكى دارد مدل انعطافيذير را مىدهد. اين خاصيت شبكؤ عصبى عميق رادي رادي

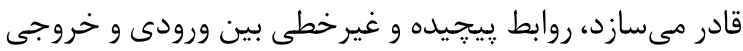

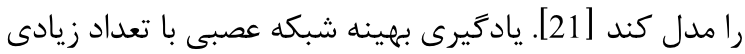

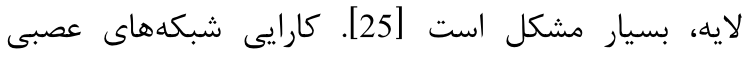

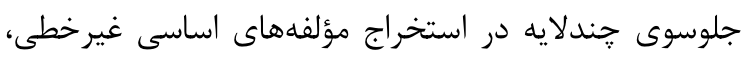
حذف نوفه و بهسازى سيخنال كفتار نشان داده شده است است استئ

نتايج بهدستآمده از بازشناسى كفتار نشان مىدهد كه

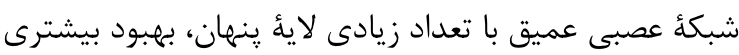
نسبت به مدل مخلوط گاوسى بر روى دادكان مرجع داشته

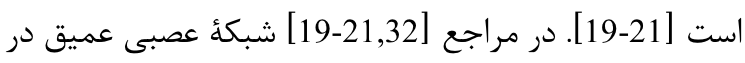
تركيب با مدل مخفى ماركف، بر روى دادكان بزرك بازشناسى

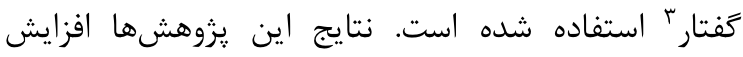
جشمثير دقت بازشناسى، نسبت به روش آموزشى -تمايزى إنى

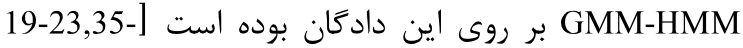

روش ديكرى كه در يزوهشهاى كنونى رقيب اصلى

روش DNN-HMMs شد،

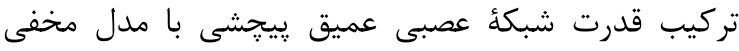

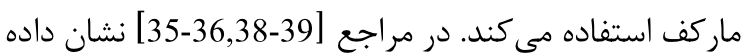
شده است كه در دادكان خالشبرانگيز تجارى كه براى كاربردهاى واقعى طراحى شدهاند، برجسته بر DNN-HMM و GMM-HMM غلبه مى كند كه

$$
\text { در ادامه به معرفى آن برداخته مىشود. }
$$

\footnotetext{
${ }^{1}$ Logistic Function

${ }^{2}$ Overfitting

${ }^{3}$ Large Vocabulary Speech Recognition
} 
و هر باند شامل I سطر براى I دسته ويزَّى ورودى و همهنين

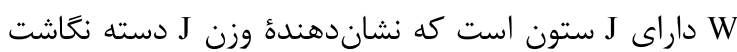

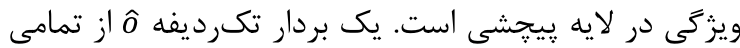
ويزكى هاى ورودى به شكل رابطؤ (9) تشكيل شده است.

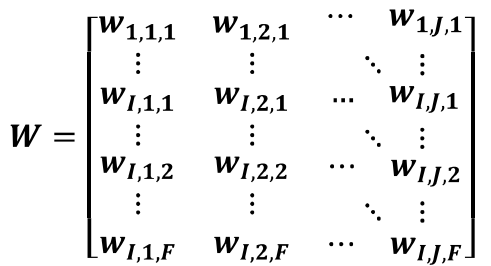

$\widehat{\boldsymbol{o}}=\left[v_{1}\left|v_{2}\right| \ldots \mid v_{M}\right]$

در اين رابطه v يك بردار سطرى شامل مقادير mأمين باند

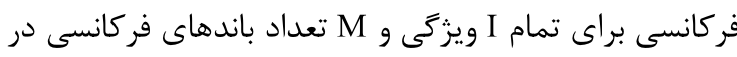

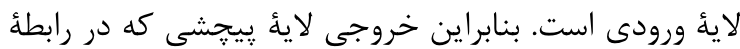

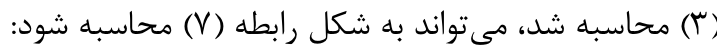
$\hat{q}=\sigma(\hat{o} \widehat{W})$

رابطه (V) داراى شكل رياضى مشابه شبكةٔ عصبى عميق است.

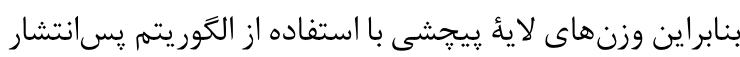

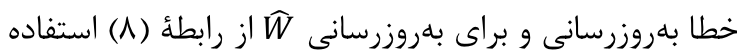

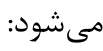

$\Delta \widehat{W}=\varepsilon \cdot \hat{o}^{\prime} e$

نحؤ رفتار با وزنهاى مشتر كى در لائُ يِيجشى با شبكة

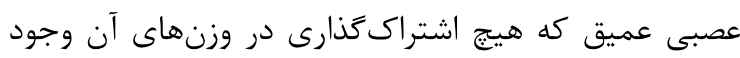

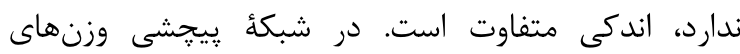
مشترك در حين بهروزرسانى، مطابق رابطه (9) جمع خواهند

$$
\Delta w_{i, j, n}=\sum_{m} \Delta \widehat{W}_{i+(m+n-2) \times I, j+(m-1) \times J}
$$

در اين رابطه I و بهترتيب نشاندهندة تعداد نكاشت

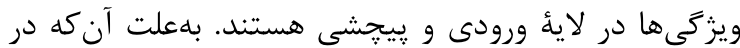

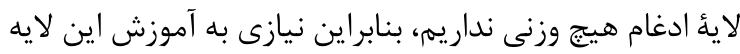
نيست؛ اما سيخنال خطا مىبايست از طريق نائ تابعايع ادغام باريه

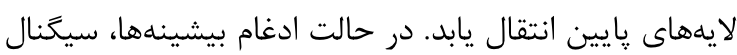

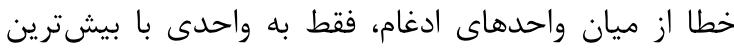

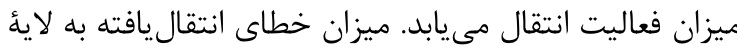
ي يجيجشى مطابق رابطه (• () قابل محاسبه است.

\section{${ }^{3}$ Pooling size}

${ }^{4}$ Max-pooling
ويثگى هاى محلى ورودى را دريافت مى كند. دوم اينكه،

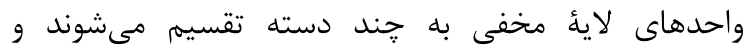
واحدهايى كه در يك دسته قرار دارند، داراى وزنه دانهاى

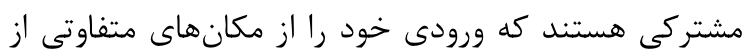
ورودى در لايهٔ يايينى دريافت مى كنيند.

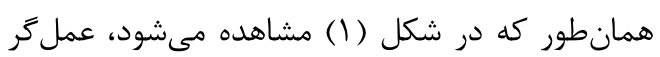

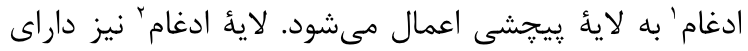

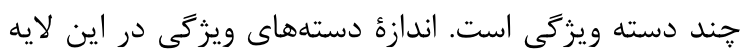

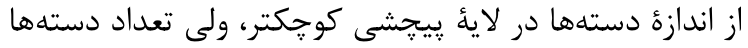
در هر دو لايه يكسان است. هدف لائ ادغام كاهش ابعاد هر

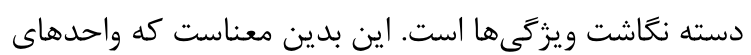

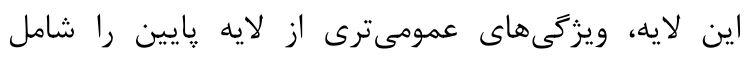

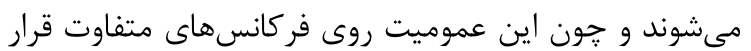

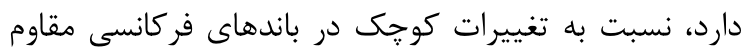

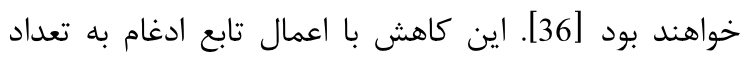
زيادى نواحى محلى در لائ يِيجشى با اندازهاى برابر اندازئ

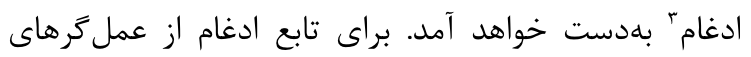

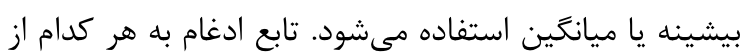

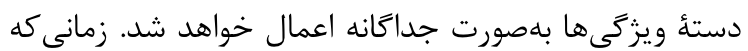
تابع ادغامَ بيشينه مورد استفاده قرار مى خيرد، لائُ ادغام

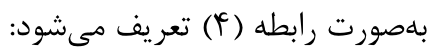
$p_{i, m}=$ $\max _{n=1}^{G} q_{i}(m-1) \times s+n$

در اين رابطه G اندازء ادغام و s اندازء شيفت و تعداد

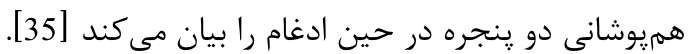

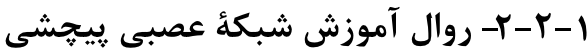
آموزش وزنها در لائُ يِيجشى با اعمال تغييراتى در الكوريتم

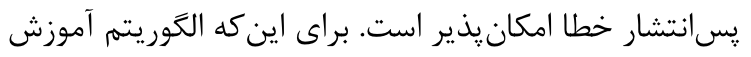

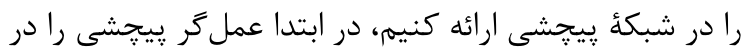

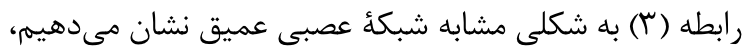

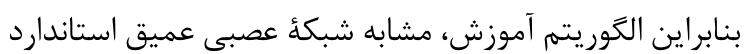

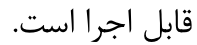

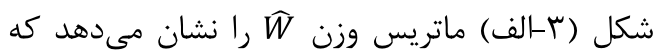

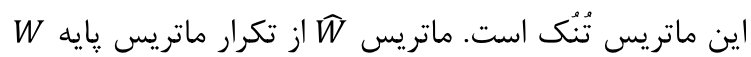

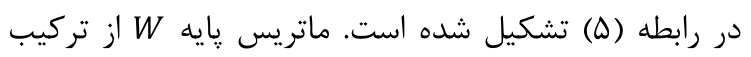

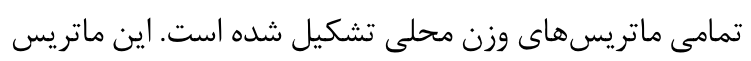
سطر است كه در آن F نشاندهندة اندازه فيلتر

\footnotetext{
${ }^{1}$ Pooling operation
}

${ }^{2}$ Pooling ply 


$$
\begin{aligned}
& \text { است. uni,m انديس واحد با بيشترين مقدار از بين واحدهاى } \\
& \sum_{m}^{e_{i, n}^{\text {low }}}=
\end{aligned}
$$

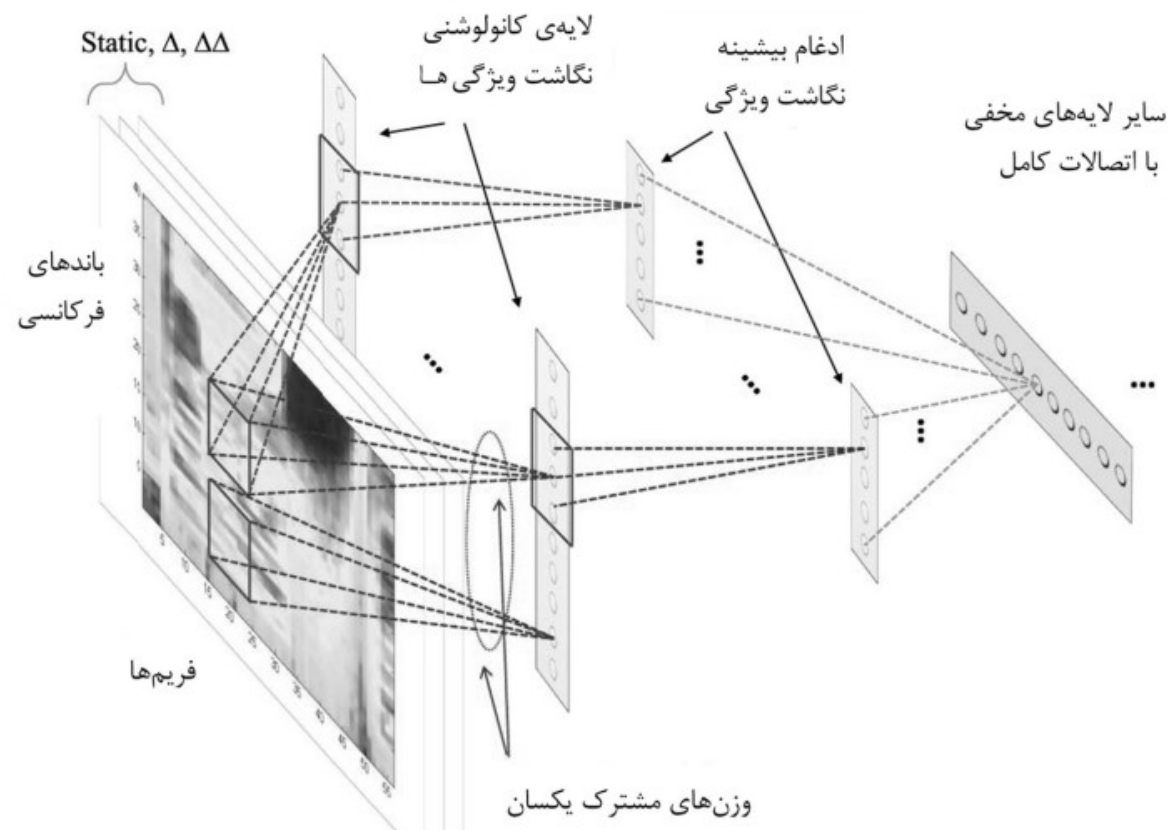

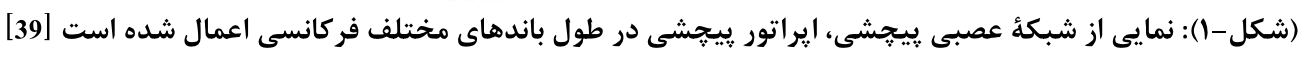

(Figure-1): A representation of Convolutional deep Neural Network (CNN), the convolution operator is applied along different frequency bands [39]

نكاشت ويزٔى هاى ورودى

$\mathbf{0}_{i}(i=1,2, \ldots, I)$

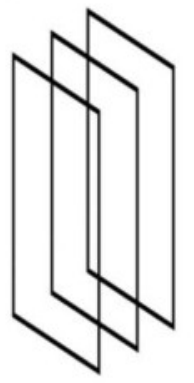

لايهى ورودى
نكاشت ويزٔكى هاى كانولوشن

$\mathbf{Q}_{j}(j=1,2, \ldots, J)$

نكاشت ويزٔكى هاى ادغام

$\mathbf{P}_{j}(j=1,2, \ldots, J)$
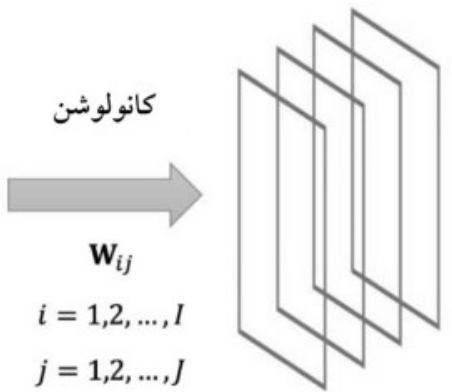

لايهى كانولوشن

لايهى ادغام

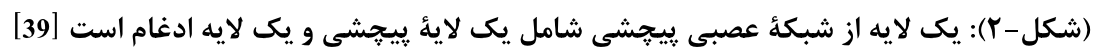

(Figure-2): A convolutional neural network layer contains a convolution layer and one pooling layer [39] 
ارديف براى

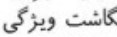

مثانداوت در هر

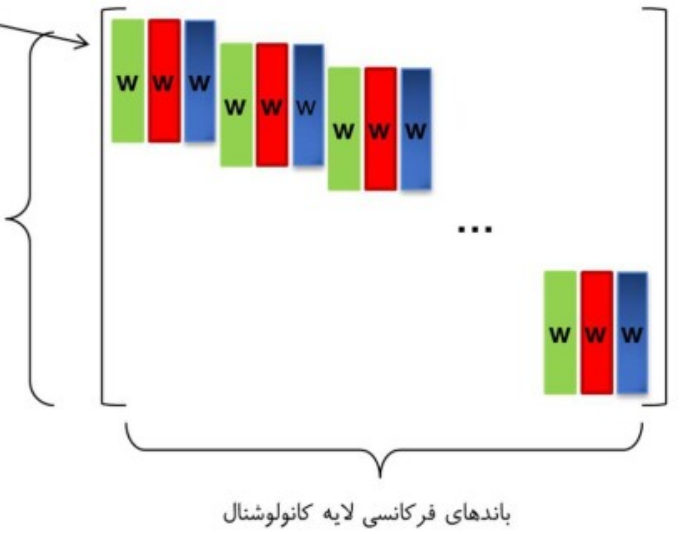

(ب)

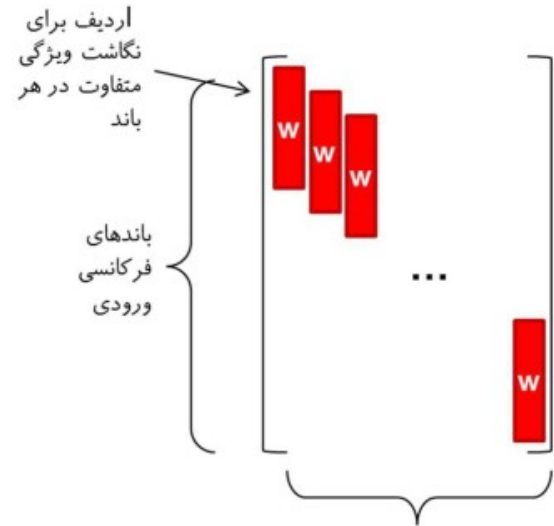

باندهاى فركانسى لايه كانولوشنال

(الف)

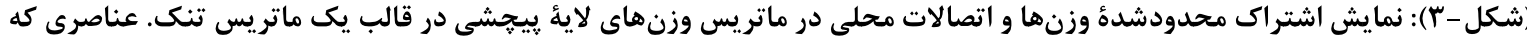

نشان داده نشدهاند، صفر هستند دانت

(Figure-3): Limited weight sharing and local connectivity in the convolutional layers shown as sparse matrix. This representation does not show zero elements.

ورودى استفاده مىشود؛ زيرا طيفنگار سيخنال كفتار

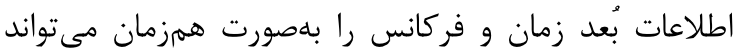

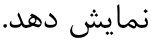

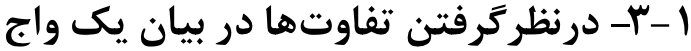

يكى از مشكلات اساسى بازشناسى كَفتار، تفاوت در بيان

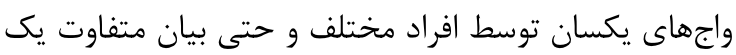

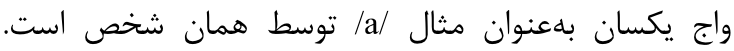

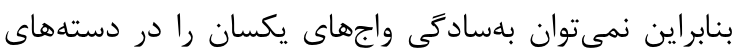

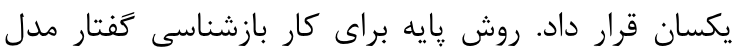

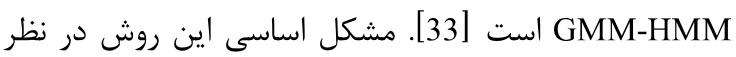

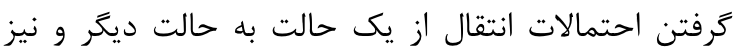
احتمالات يسين يك مشاهده بهصورت فرمولى ثابت است. اين

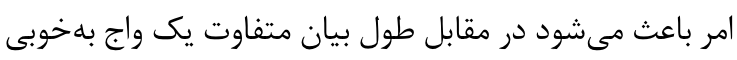

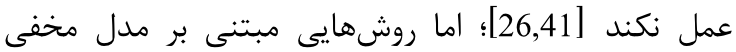
ماركوف مانند HSMMو HSHMM ارائه شدهاند كه حالات

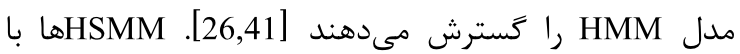

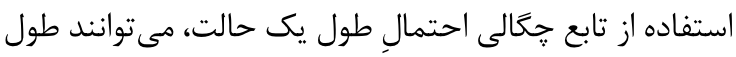

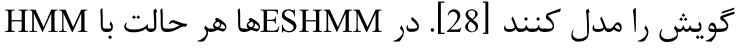
ديخرى جايخزين مى شود؛ بنابراين طول تابع جُّالى احتمال

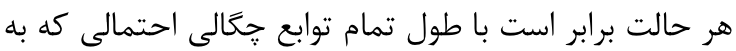

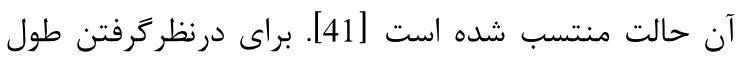

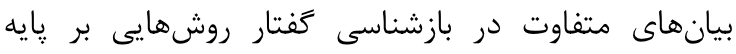

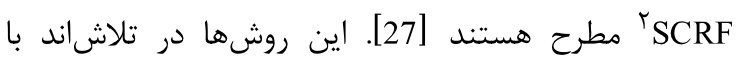

${ }^{2}$ Segmental Conditional Random Fields (SCRF)

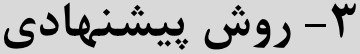

در دهؤ كنونى شبكههاى عميق از جديدترين و قوىترين ابزارهاى يردازش كفتار در مقايسه با ساير روشها مها محسوب مىشوند [25-19]. هدف اصلى اين مقاله بهبود ساختار و و

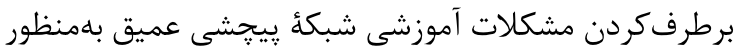

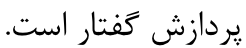

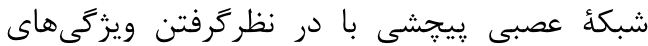

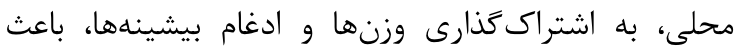

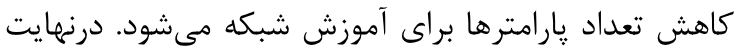

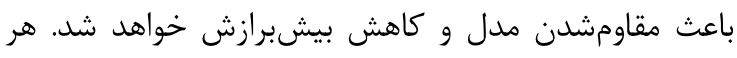

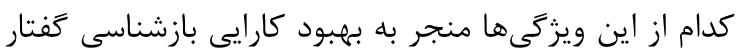

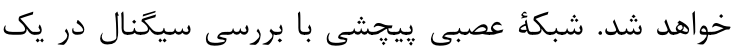

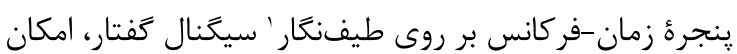
درنظرگرفتن ويزگى هاى محلى را بهصورت توأمان فران فراهم

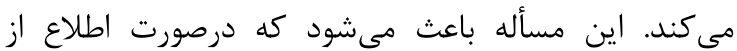
باندهاى فركانسى كه تحت تأثير نوفه قرار گرفتهاند و ياتيا

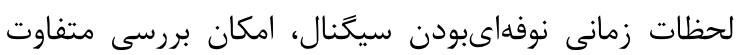
باندهاى فركانسى و لحظات زمانى مختلف فراهم شود.

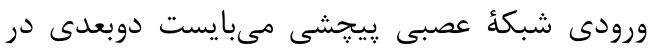

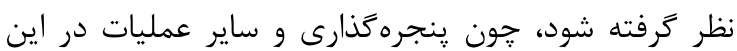

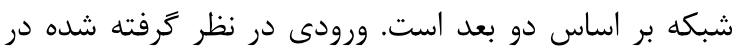
مقالات [35-36,39] نمودار طيفنغار است. به جاى اسى نمودار

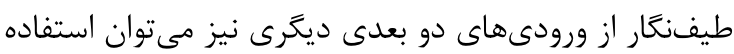
كرد. در اين مقاله نيز از طيفنگار سيگنال كفتار به ديه عنوان

${ }^{1}$ Spectrogram 
درصورتى كه سه طول مختلف براى ينجرهها در نظر كرفته

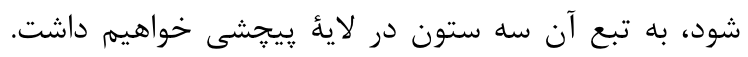

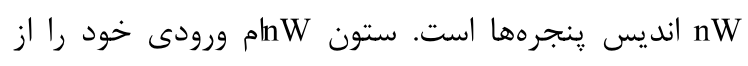

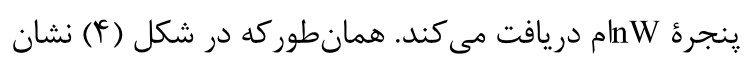
داده شده است، ويزگ هاى

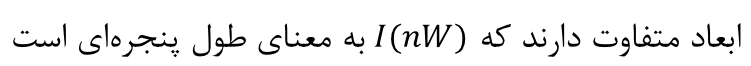

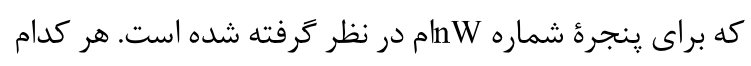

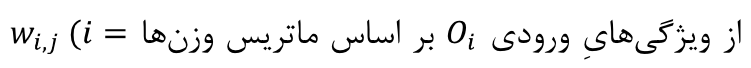
$Q_{j}(j=1,1, \ldots, I ; j=1, \ldots, J)$

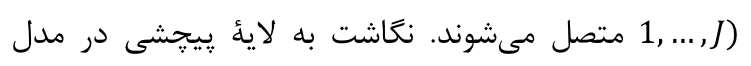

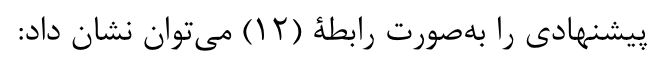

$$
\begin{aligned}
& q_{j, m, n W}= \\
& \sigma\left(\sum_{i=1}^{I(n W)} \sum_{n=1}^{F} o_{i, n+m-1} w_{i, j, n}+w_{0, j}\right), \\
& (j=1, \ldots, J ; n W=1, \ldots, N W)
\end{aligned}
$$

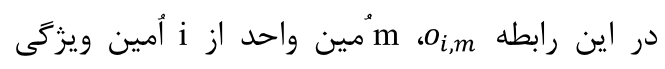
ورودى است. F اندازه فيلتر است، كه تعيين كنندة تعداد

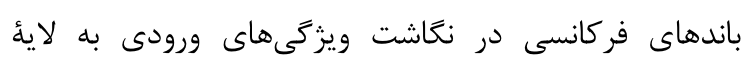

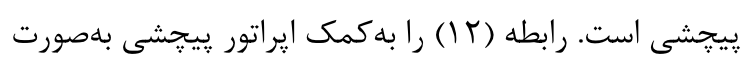

$$
\begin{aligned}
& Q_{j, n W}=\sigma\left(\sum_{i=1}^{I(n W)} O_{i} * w_{i, j}\right) \\
& (j=1, \ldots, J ; n W=1, \ldots, N W)
\end{aligned}
$$

تعداد دسته نحاشتهاى ويزگى در لائ يِيجشى بهطور

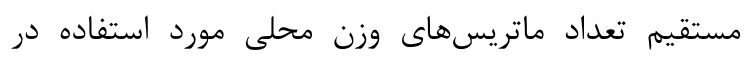

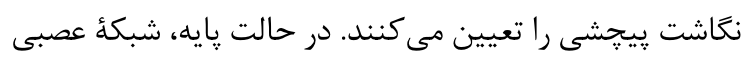

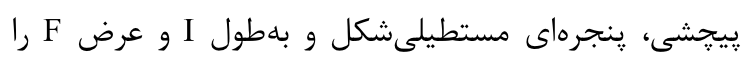
مورد بررسى قرار مى دهد. براى ارتباط بين لائُ پِيجشى و لائه ادغام ميانكين،

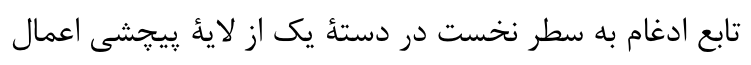

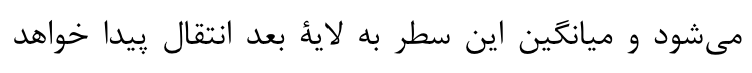

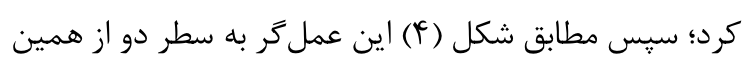

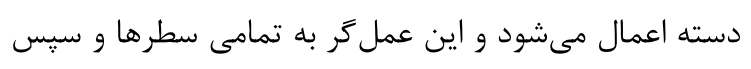

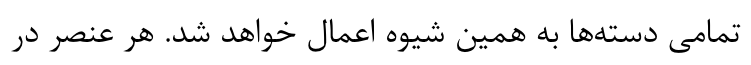

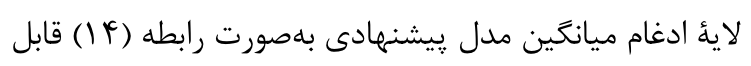

$$
t_{j, m}=r \sum_{n W=1}^{N W} q_{j, m, n W}
$$

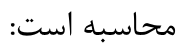

${ }^{2}$ Convolutional neural network ${ }^{3}$ Unit
استخراج ويزگى هايى كه بيانگر طول بيان متفاوت هستند و

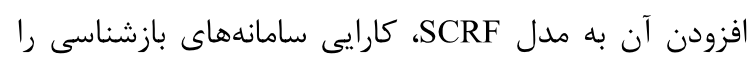

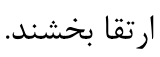

روشى كه در اين مقاله بيان مىشود، بر پائَ شبكة

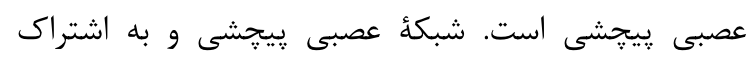

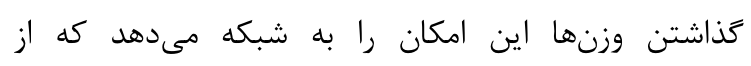

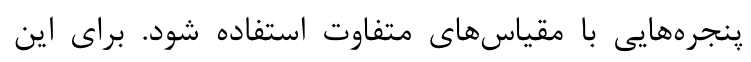

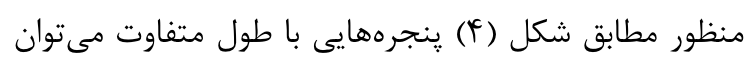

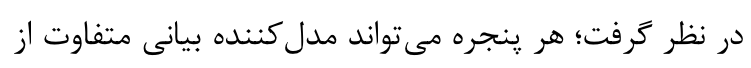

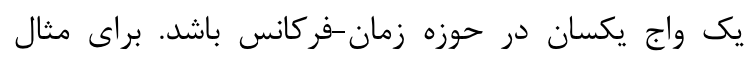

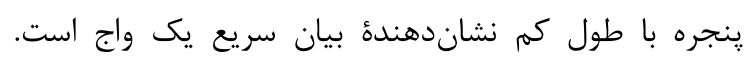

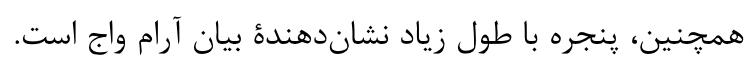

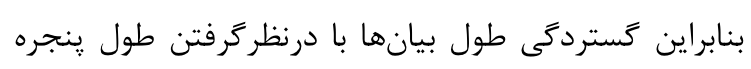

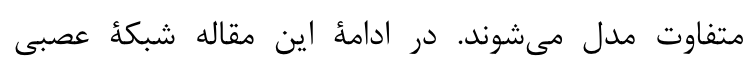

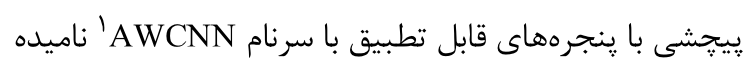

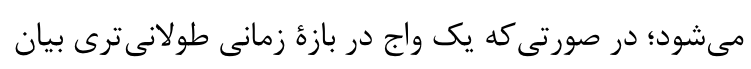

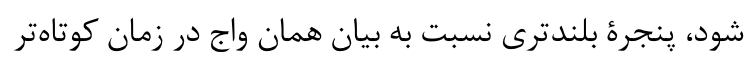

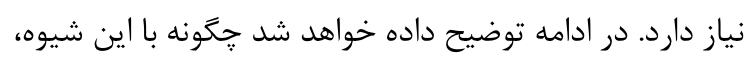

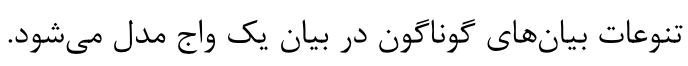

\section{AWCNN-HMM - r-r}

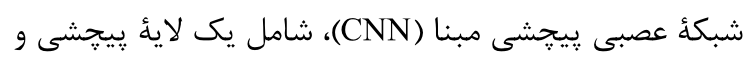

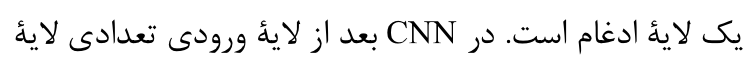

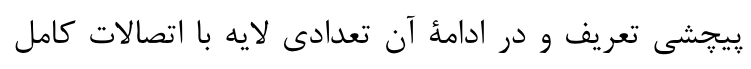

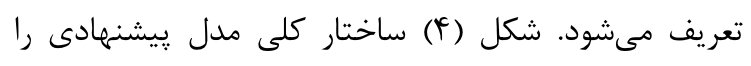

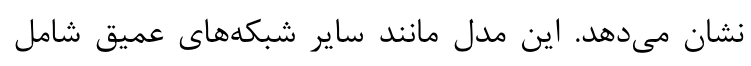

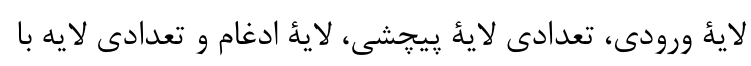

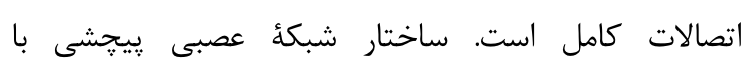

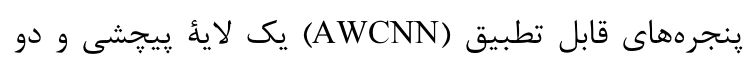

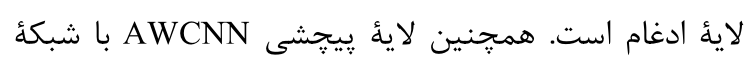

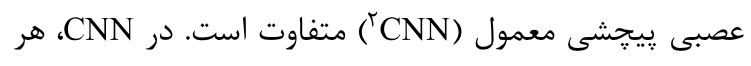

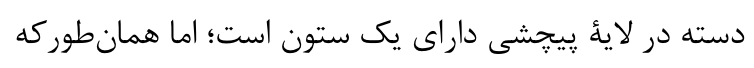

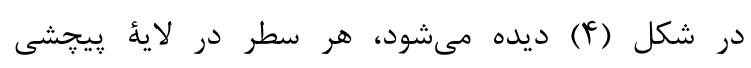
AWCNN

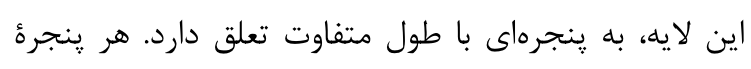

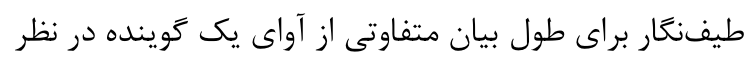

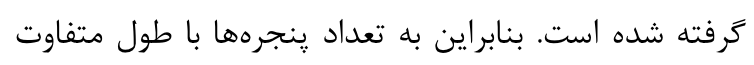

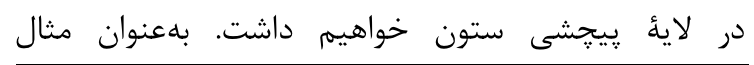

1 Adaptive Windows Convolutional Neural Network (AWCNN) 


$$
p_{j, m}=\max _{n=1}^{G} t_{j}(m-1) \times s+n
$$

اين فرمول درواقع نحوه محاسبه هر عنصر در لايةٔ ادغام

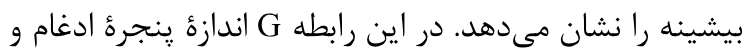
s بيان مى كند.
در اين رابطه r ضريب نرمال سازى است. براى عمل

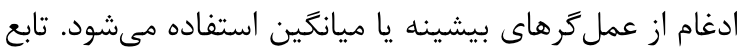

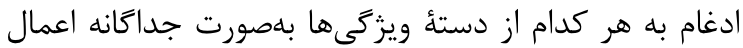
خواهد شد.

در مرحلة بعد تابع ادغام بيشينه به لائُ ادغام ميانكً

اعمال مىشود. تابع ادغام بيشينه نيز بهصورت رابطه (ها (ا) تعريف مىشود:

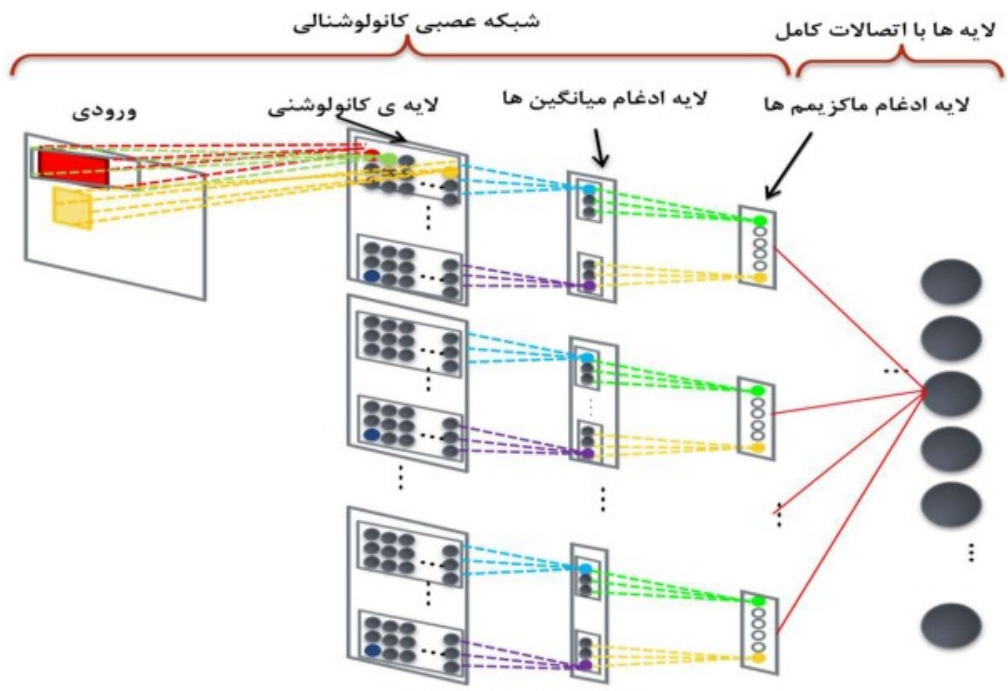

كانولوشئ

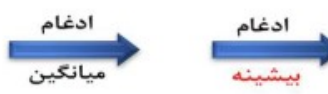

AWCNN شكل - F): نمايش شبكه عصبى عميق بيشنهادى

(Figure-4): A representation of the proposed method (AWCNN)

رابطه (ها ) اعمال خواهد شد.

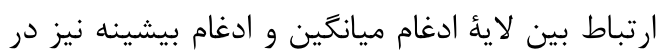

شكل (9) نشان داده شده است. بعد از لائٔ ادغام بيشينه

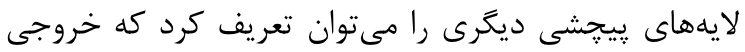

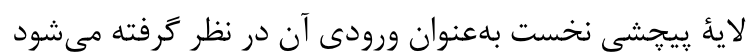
و نحوه آموزش آن نيز به همين صورت است.
همانطور كه در شكل (ه) نشان داده شده، إيراتور

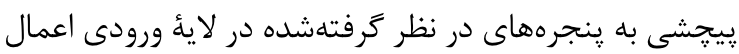

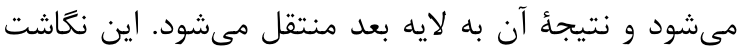
توسط ايراتور ״يجڤشى در مباحث يردازش سيخنال مطابق

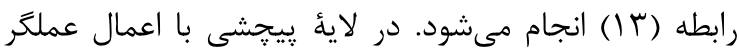

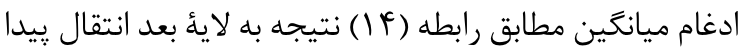
مى كند. در لايئ ادغام بيشينه نيز ايراتور ادغام بيشينه مطابق
ورودى

$o_{i}(i=1, \ldots, I(n W))$

نكاشت ويزكّى هاى كانولوشن

(9)

$T_{j}(j=1, \ldots, D)$

$P_{f}(j=1, \ldots, J)$
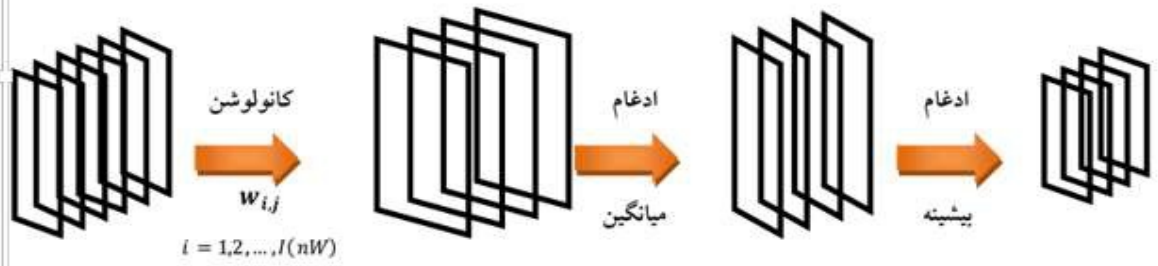

$$
j=1,2, \ldots, j
$$

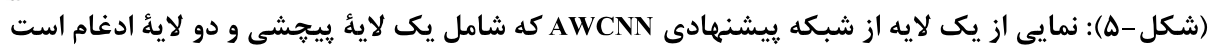

(Figure-5): An illustration of one layer of the proposed method containing one convolution layer and two pooling layers 
مى كذارد. علت مقايسٔ اين الكَوريتمها اين است كه هر دو در

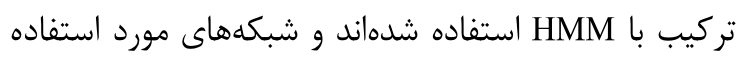

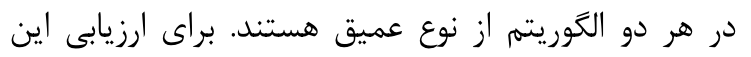

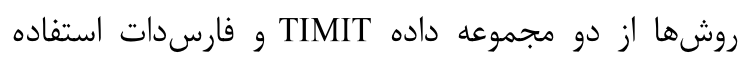

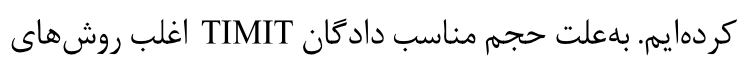
پيشنهادى جهانى بر روى آن ارزيابى شدهاند. بنابراين امكان

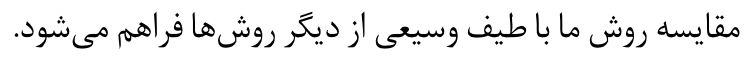

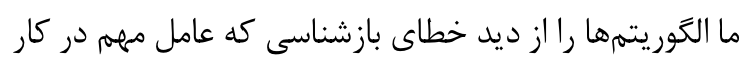

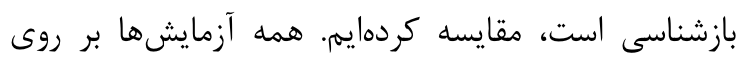
رايانهاى داراى يردازنده 2.88GHz هشت هستهاى و حافظه GPU به ظرفيت r RAM

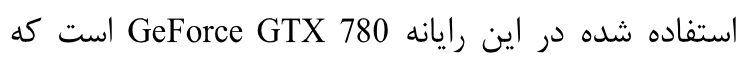

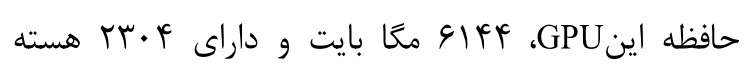

$$
\text { يردازشى كودا' است. }
$$

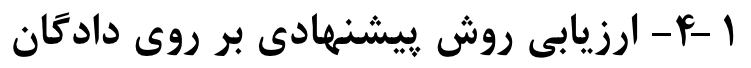

TIMIT

تمام آزمايشهاى اين قسمت بر روى مجموعه هسته اصلى

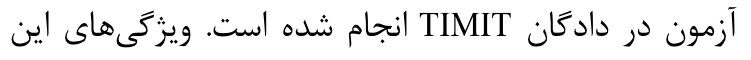
مجموعهدادهها در جدول (1) نشان داده شدهاند. همان كونه

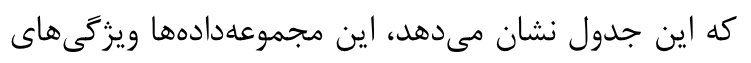

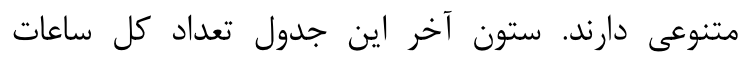

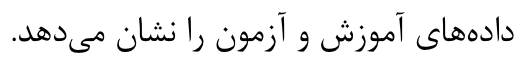

(جدول-1): ويرَّى هاى مجموعه دادهاى TIMIT مورد استفاده

$$
\text { در آزمايشها }
$$

\begin{tabular}{|c|c|c|c|}
\hline \multicolumn{4}{|c|}{ experimentations } \\
\hline ساعات داده & تعداد & تويندكان & مجموعه داده \\
\hline 3.14 & 3696 & 462 & آموزش \\
\hline 0.16 & 192 & 24 & هسته مركزى آزمون \\
\hline 0.81 & 1344 & 168 & مجموعه كامل آزمون \\
\hline
\end{tabular}

(Table-1): Characteristics of TIMIT dataset used in the

آزمايشهاى مختلفى براى ارزيابى روش ريشنهادى

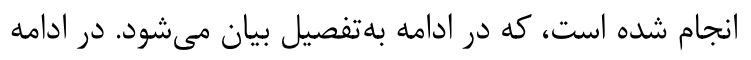

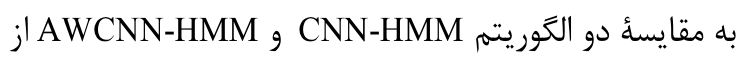
نظر خطاى بازشناسى واج و توصيف نتايج آزمايشهاى

$$
\text { انجامشده بر روى دادكان TIMIT مي يردازيم. }
$$

در آزمايش نخست هر دو الكوريتم،

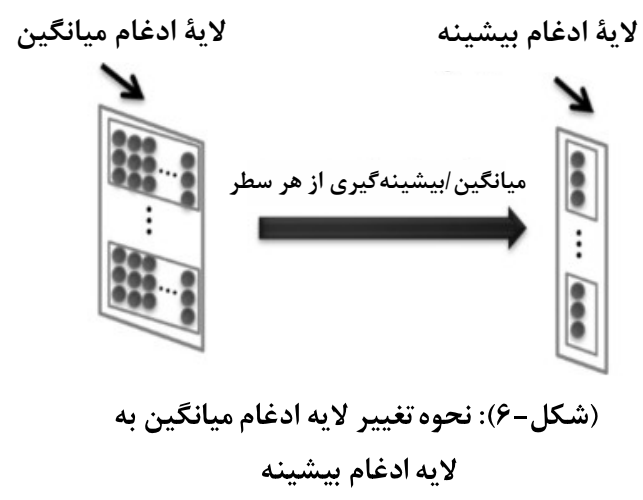

(Figure-6): Mean-pooling layer conversion to max-pooling layer

همجنين همانطور كه در شكل (\&) نشان داديم،

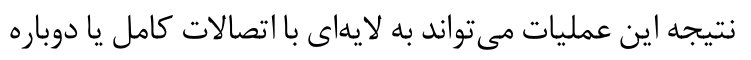

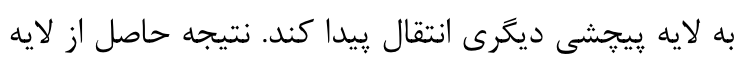

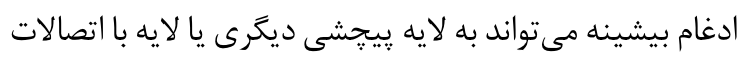

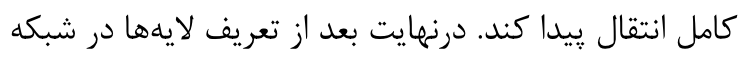

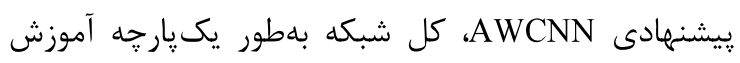

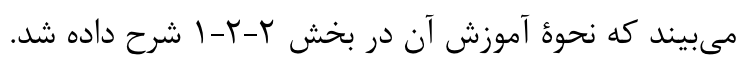

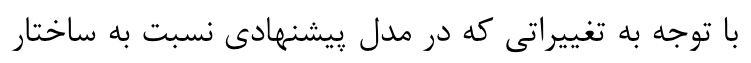

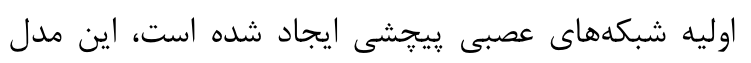

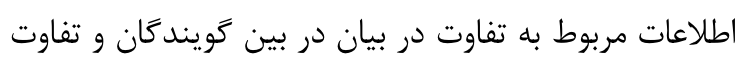
در بيانهاى يك توينده را مىتواند مدل كند.

\section{F}

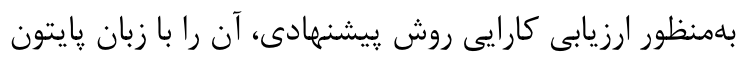

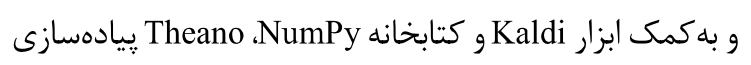
و با الكوريتمهايى جون DNN-HMM و [13] مقايسه خواهيم كرد. Theano يك كتابخانه براى تعريف،

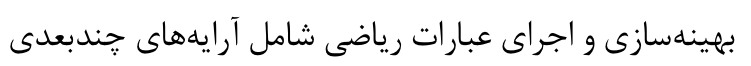

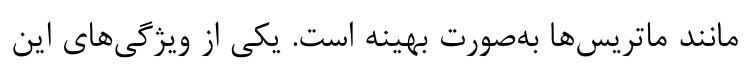

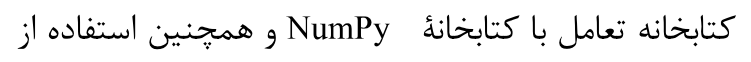
براى تسريع عمليات مشتق كيرى عبارات رياضى است.

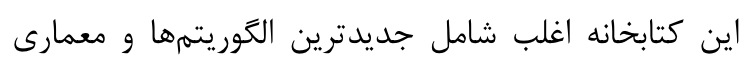

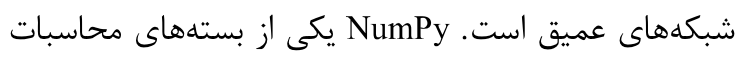

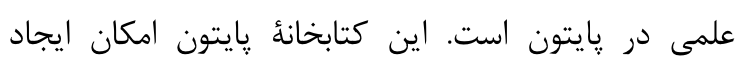

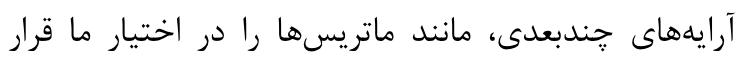

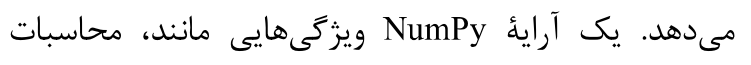

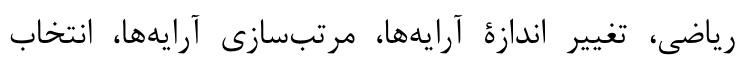

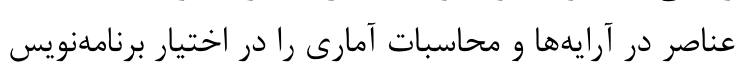


درنظرگرفتن اندازه خيلى بزرى براى ينجرهها احتمال ورود

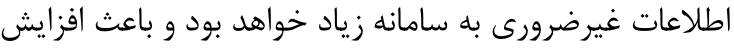
خطاى بازشناسى واج خواهد شد.

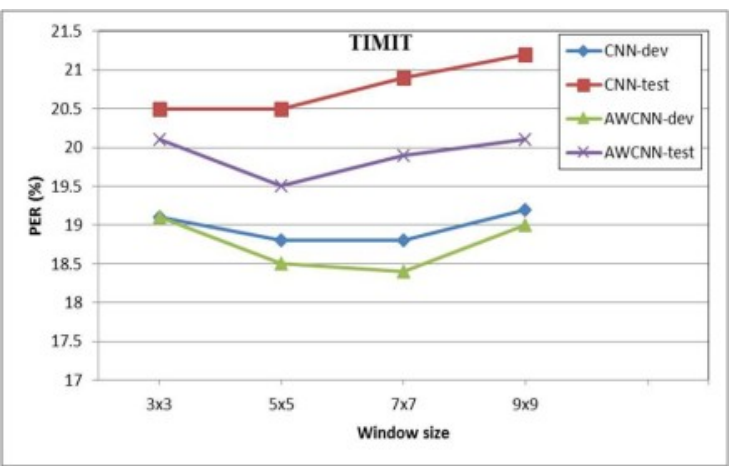

(شكل - V): بررسى كارايى دو الخوريتم (AWCNN CNN) و تاثير

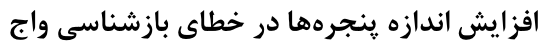

(Figure-7): The effect of the different window sizes on the error rates of CNN and AWCNN algorithms

در آزمايش دوم تأثير افزايش تعداد لايههاى با اتصالات

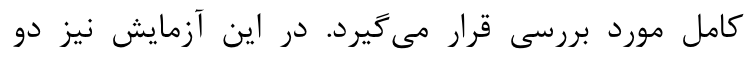

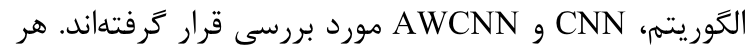

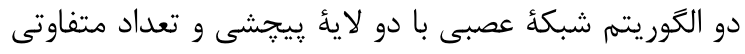

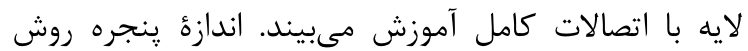
AWCNN-HMM ينجره در روش CNN-HMM، ه×ه در نظر گرفته شده است. محور افقى نشاندهنده تعداد لايهها با اتصالات كامل و محور لطري عمودى نشاندهنده خطاى بازشناسى واج است. براى مثال

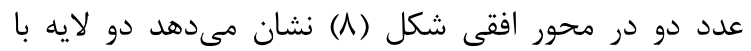
اتصالات كامل در مدل ييشنههادى استفاده شده است. شكل

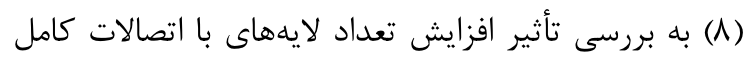

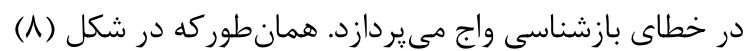
مشاهده مىشود، با افزايش عمق شبكئ عصبى با اتصالات كامل نتايج بهترى حاصل خواهد و خطاى بازشناسى كاهش مئ ئسيابد. علتبهدستآمدن نتايج بهتر با توجه به ساختار مدل ييشنهادى اين است كه با افزايش عمق، امكان بررسى برى

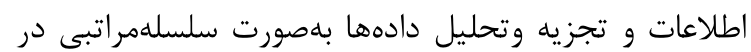
لايههاى بالاتر بهوجود خواهد آمد. در لايههاى يايينتر

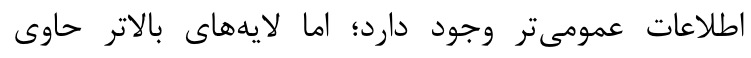
اطلاعات تمايزى هستند. همانطور كه در شكل (1) مشاهده مىشود، افزايش تعداد لايههاى مخفى سبب افزايش دقت

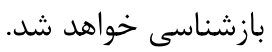
در آزمايش بعد الكوريتمهاى متفاوت مانند: -CNN , , DNN-HMM , AWCNN-HMM ،HMM
مورد بررسى قرار گرفتهاند. هر دو الخوريتم در تركيب با مدل استفاده شده است كه در ادامه بلهترتيب با سرنام AWCNN-HMM , CNN-HMM ذكر خواهند شد. در هر

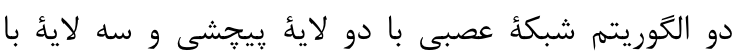

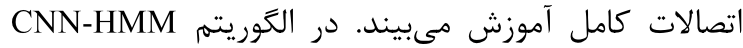
شبكة عصبى عميق ڤيجشى كه در مرجع [35-36] اشاره شده، بهعنوان روش يايه مورد استفاده قرار گرفته است. در اين

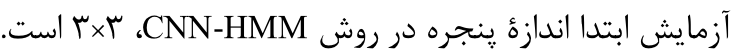

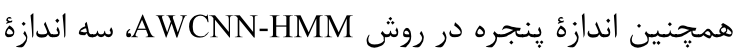
متفاوت س

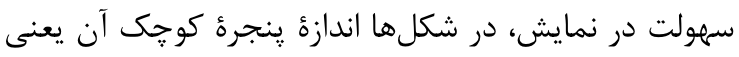

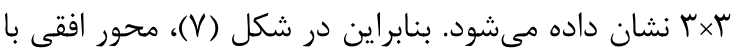
عدد، ه×D براى روش AWCNN-HMM به معنى سه ينجره

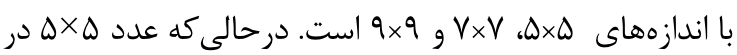
روى محور، براى روش CNN-HMM نمايانگ يك شبكئ

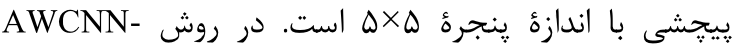

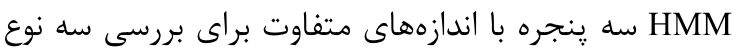

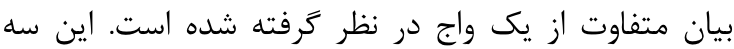
ينجرءٔ متفاوت براى درنظر گرفتن سه طول متفاوت از يك بيان

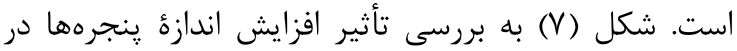

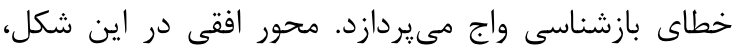

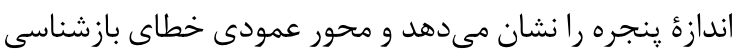

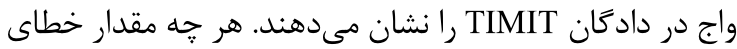
بازشناسى، كمتر شود، نتيجه مطلوبتر است؛ زيرا نشان

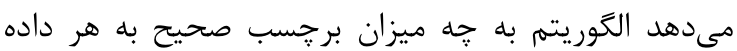
نسبت داده است. همانطور كه در شكل (V) مشاهده مىشود،

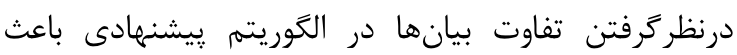
افزايش كارايى آن شده است. همانطوركه در اين شكل نشان

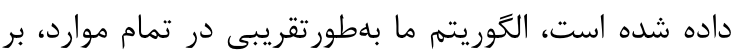

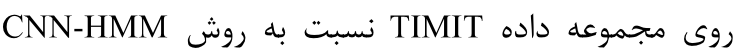
نتايج بهترى كسب كرده است. علت بهدست آمدن نتايج بهتر

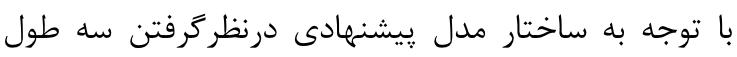

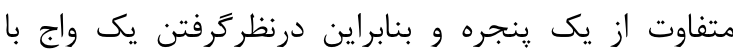

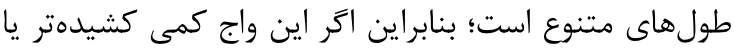

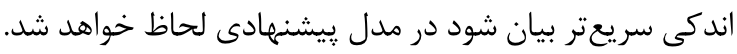
همانطوركه در شكل (V) مشاهده مىشود، در صورتى كه

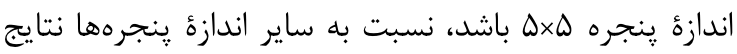

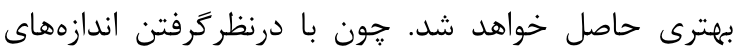

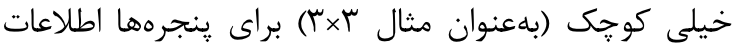

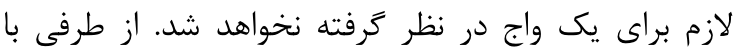




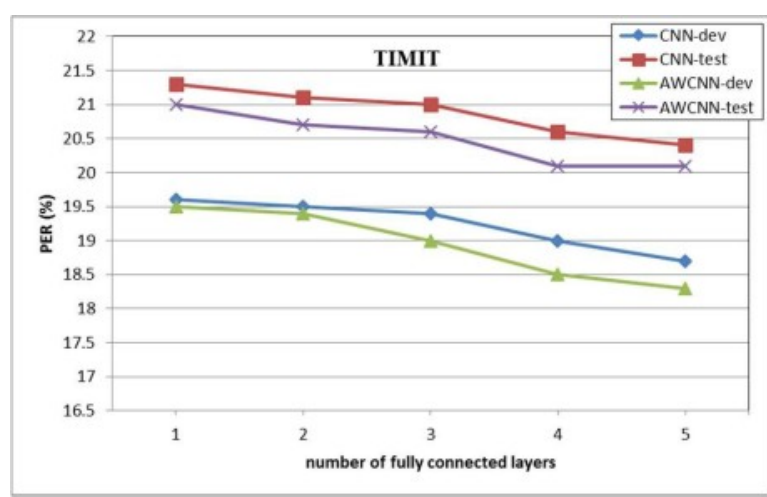

(شكل -^): مقايسةٔ دو الكوريتم (CNN و (AWCNN) و بر رسى تأثير افزايش تعداد لايههاى با اتصالات كامل

(Figure-8): The effect of different number of fully connected layers on CNN and AWCNN algorithms
خواهيم كرد. اين نتايج در جدول (r) قابل مشاهده هستند. در جدول (Y)، LWS نشاندهنده اشتراك كذارى محدودشده

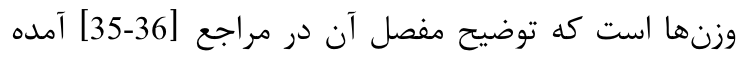

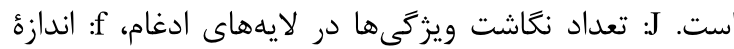

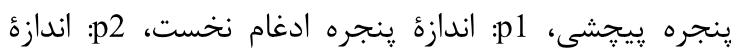

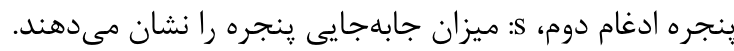

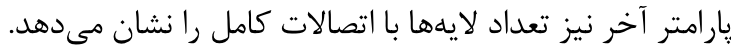

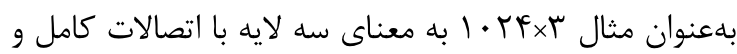
داراى Fr • ا نرون در هر لايه است. تعداد لايههاى شبكة

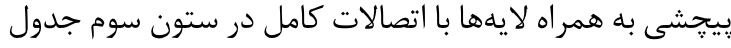

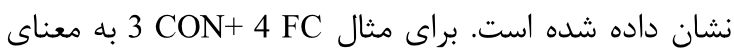
وجود سه لائَ يِيجشى و جهار لائُ با اتصالات كامل است.

(جدول-Y) : خطاى بازشناسى واج بر روى دادكان TIMIT

(Table-2): Phone Error Rate (PER\%) on TIMIT dataset

\begin{tabular}{|c|c|c|c|c|}
\hline$\hat{\mathfrak{a}}$ & مدل & 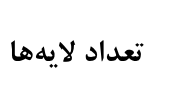 & خطاى داده & توسعه (PER/. \\
\hline 1 & CNN-HMM $\{2 \times \operatorname{LWS}(\mathrm{j}: 75$ p1:3 s:1 f:5) $+3 \times 1024\}$ & 2 Conv $+3 \mathrm{FC}$ & 20.5 & 18.8 \\
\hline 2 & AWCNN-HMM $\{2 \times \operatorname{LWS}(\mathrm{j}: 75$ p1:3 p2:4 s:1 f:5) $+3 \times 1024\}$ & $2 \mathrm{Conv}+3 \mathrm{FC}$ & 19.5 & 18.5 \\
\hline 3 & DNN-HMM \{pre-training $+4 \times 1024\}$ & 4FC & 22.9 & 21.0 \\
\hline 4 & CNN-HMM $\{2 \times$ LWS(j:147 p1:3 s:1 f:7)+10×1024\} & 2 Conv $+10 \mathrm{FC}$ & 20.8 & 19 \\
\hline 5 & AWCNN-HMM $\{2 \times$ LWS(j:147 p1:3 p2:4 s:1 f:7)+10×1024\} & $2 \mathrm{Conv}+10 \mathrm{FC}$ & 20.5 & 19 \\
\hline 6 & CNN-Res-HMM $\{6 \times \operatorname{LWS}(\mathrm{j}: 75 \mathrm{p}: 1 \times 1 \mathrm{~s}: 1 \mathrm{f:} 3)+3 \times 1024\}$ & $6 \mathrm{Cov}+3 \mathrm{Fc}$ & 20.3 & 18.5 \\
\hline 7 & AWCNN-Res-HMM $\{6 \times$ LWS(j:75 p1:1×1 p2:1×3 s:1 f:5+3×1024\} & $6 \mathrm{Cov}+3 \mathrm{Fc}$ & 19.4 & 18.0 \\
\hline
\end{tabular}

بالايى بهخوبى صورت نيذيرد. همجنين مقايسُٔ سطرهاى دو

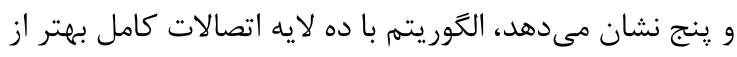

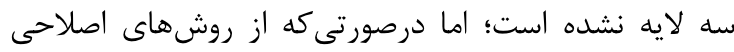

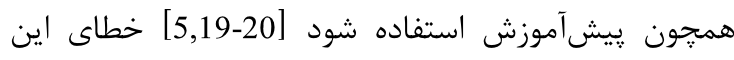
روشها كاهش خواهد يافت. در سطرهاى شش و هونت هفت جدول

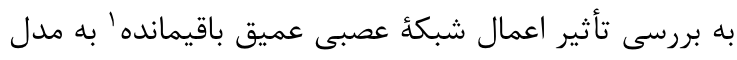

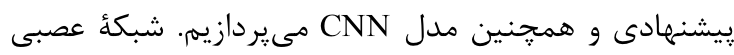
باقىمانده با سرنام Res به CNN و AWCNN

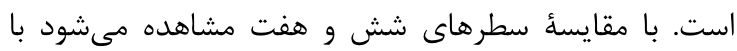
اعمال مدلٍ AWCNN-Res-HMM با شش لايئ ييجشى و و سه لايه با اتصالات كامل، خطاى مطلق نسبت به - CNN-Res-

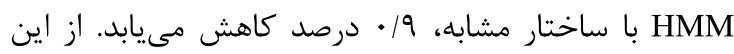

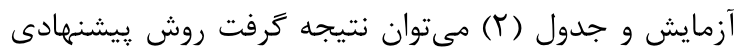

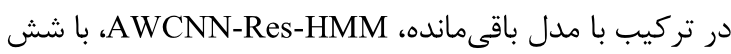

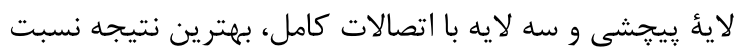

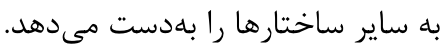

\footnotetext{
${ }^{1}$ Deep Residual Learning
}

در اين آزمايش براى روش پيشنهادى هر دو ادغام، بيشينه در نظر كرفته شده است. در جدول (r) از مقايسه سطر

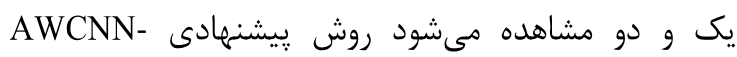

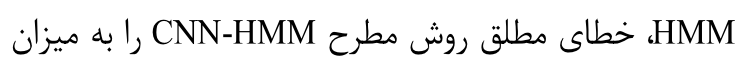
يك درصد كاهش داده است؛ قابل ذكر است، هر دو مدل داراى داى دإن

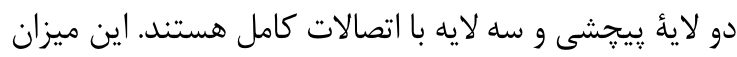
بهبود، قابل قبول براى كار بازشناسى كفتار بهشمار مى آيد.

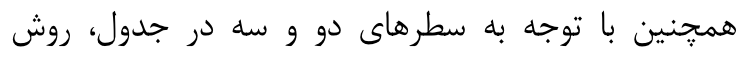

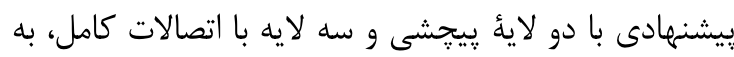

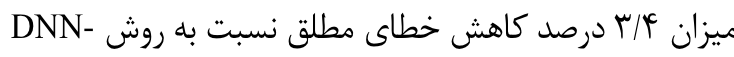

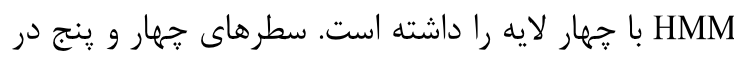

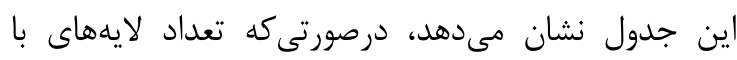

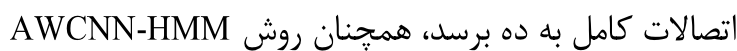
بر روش CNN-HMM برترى دارد؛ ولى افزايش زياد تعداد لايهها سبب مىشود كردش اطلاعات بلخصوص در لايههاى درى 
مشاهده مىشود با اعمال مدلٍ AWCNN-Res-HMM بالإل هفت لائ يِيجشى و سه لايه با اتصالات كامل، خطاى مطلق

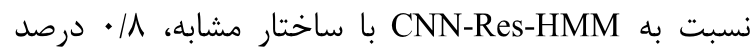
كاهش مىيابد.

در سطر شش جدول (f)، مدل - AWCNN-Res-

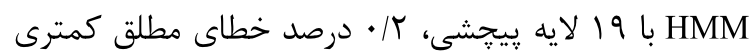
نسبت به AWCNN-Res-HMM با V لايه يِيجشى دارد. كه

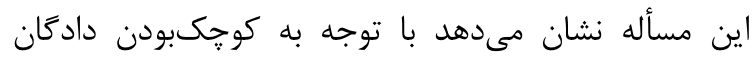

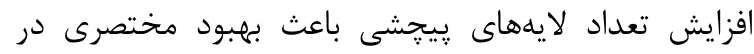

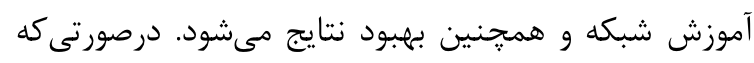

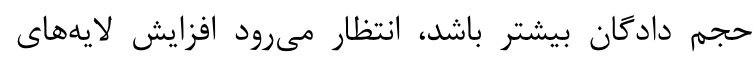
شبكه باعث بهبود بيشترى در نتايج شود.

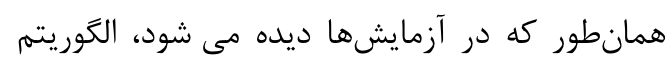
ييشنهادى AWCNN، در بيشتر موارد خطاى بازشناسى واج كمترى نسبت به روش CNN دارد. اين مسأله در همأ

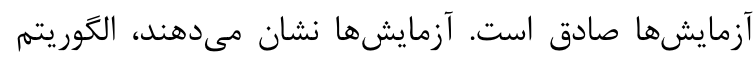

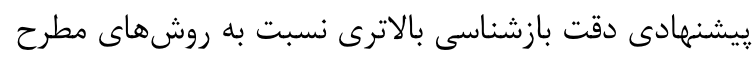

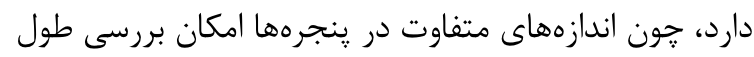

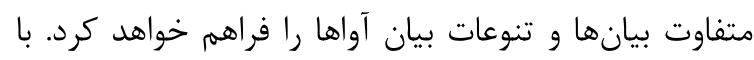

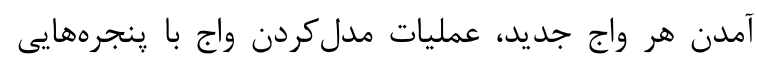

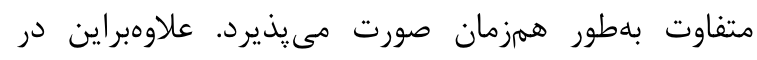

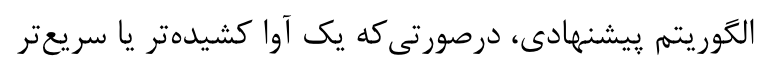

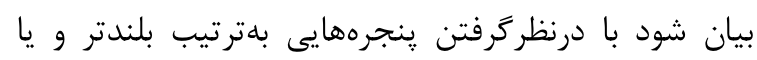

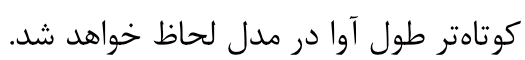

ستون هفت از جدول (\&) زمان آموزش مدلهاى عميق

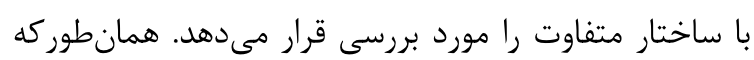

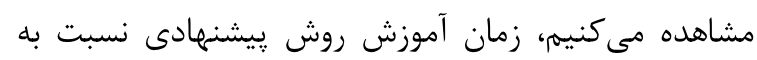

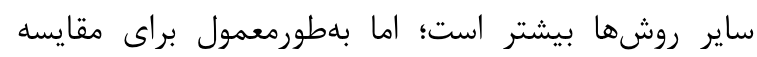

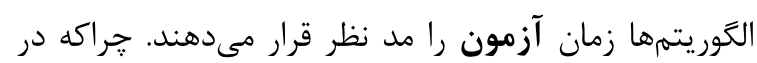

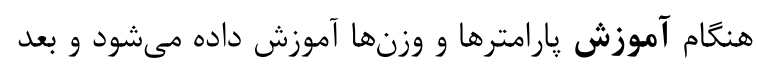

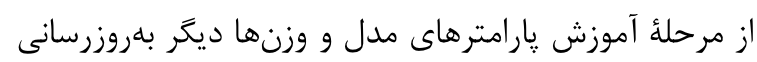

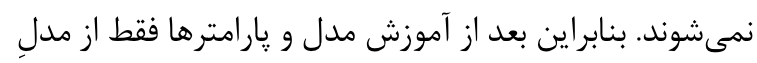

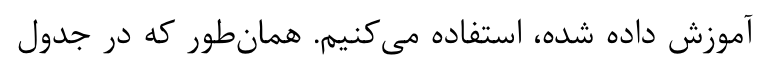

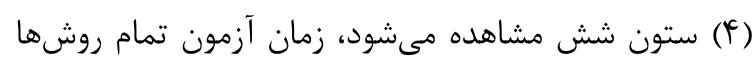

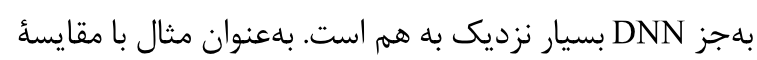

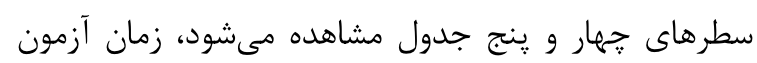

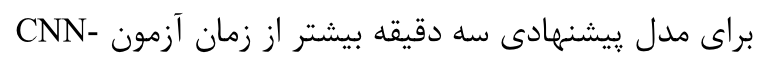

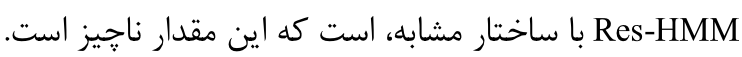

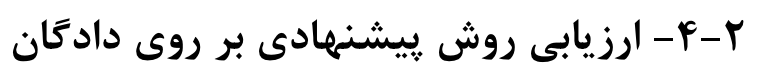

$$
\text { فارسدات }
$$

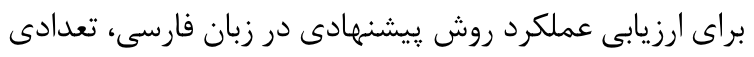

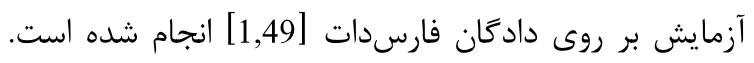

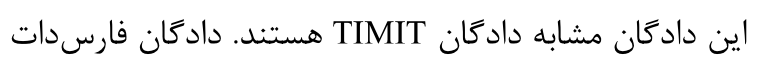

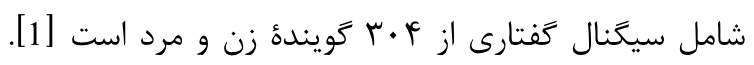

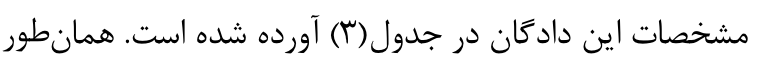

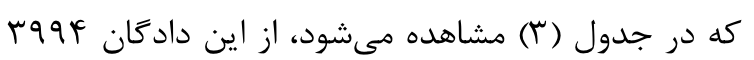

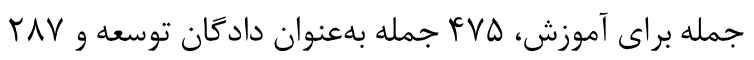

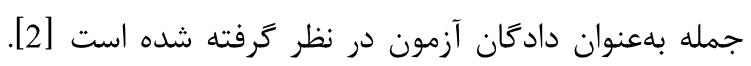

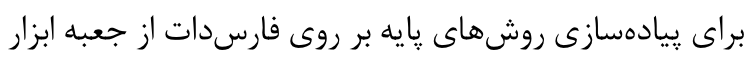
كلدى استفاده شده است [2].

(جدول - Y): ويزَّى هاى مجموعه دادههاى فارسدات مورد

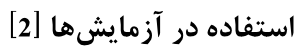

(Table-3): Characteristics of FarsDat dataset used in the

\begin{tabular}{|c|c|c|}
\hline \multicolumn{3}{|c|}{ experimentations [2] } \\
\hline تعداد & تعداد & مجموعه \\
\hline جملات & تويند & داده \\
\hline 3994 & 224 & 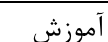 \\
\hline 475 & 50 & توسعه \\
\hline 287 & 30 & آزمون \\
\hline
\end{tabular}

در جدول (F) به مقايسٔ الكوريتهماى متفاوت مانند:

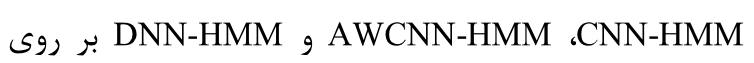
دادFان فارسدات مىيردازيه. شاخصdهاى موجود در جدول

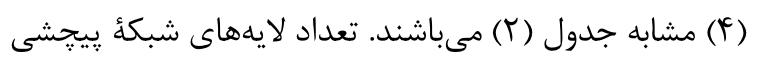

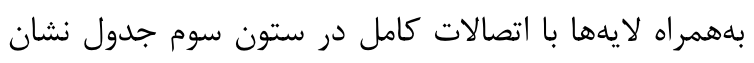

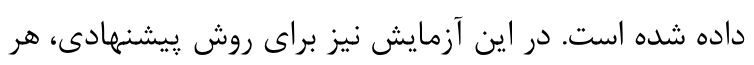

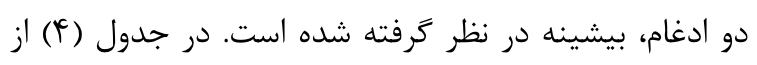

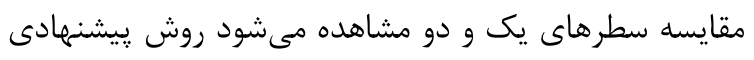

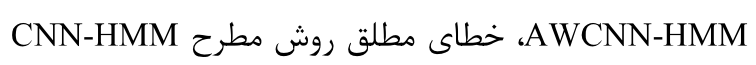

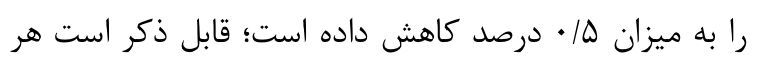

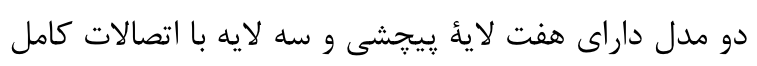

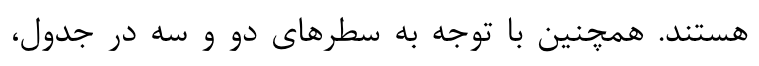

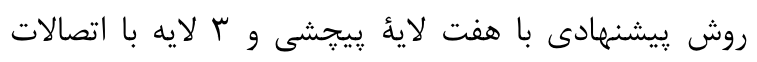

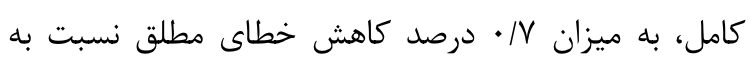

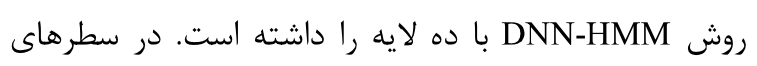

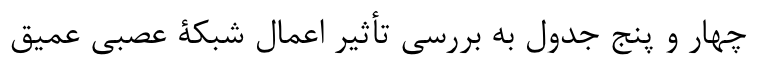

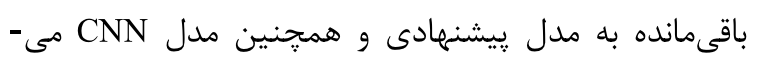

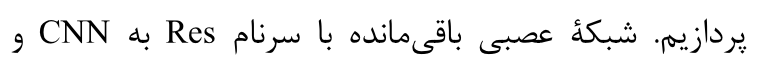

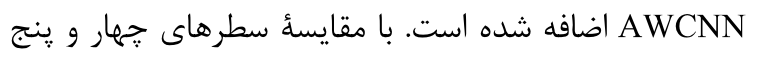


(جدول-F): خطاى بازشناسى واج بر روى دادكان فارسدات

(Table-4): Phone Error Rate (PER\%) on FarsDat dataset

\begin{tabular}{|c|c|c|c|c|c|c|}
\hline$\hat{\tilde{j}}$ & 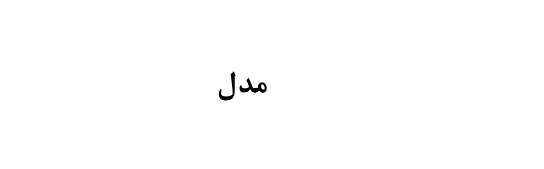 & تعداد لايهها & خطاى داده & خطاى داده & $\begin{array}{l}\text { آزمون } \\
\text { زان } \\
\text { (min) }\end{array}$ & زآموزش \\
\hline 1 & $\begin{array}{l}\text { CNN-HMM } \quad\{7 \times \operatorname{LWS}(\mathrm{j}: 75 \text { p1:3 } \\
3 \times 1024\}\end{array}$ & 7 Conv $+3 \mathrm{FC}$ & 21.7 & 21.5 & 52 & 144.6 \\
\hline 2 & $\begin{array}{l}\text { AWCNN-HMM }\{7 \times \text { LWS(j:75 p1:3 p2:4 s:1 } \\
\text { f:5) }+3 \times 1024\}\end{array}$ & 7Conv $+3 \mathrm{FC}$ & 21.2 & 21.9 & 59 & 258 \\
\hline 3 & DNN-HMM \{pre-training $+10 \times 1024\}$ & $10 \mathrm{FC}$ & 21.9 & 22.2 & 1 & 21 \\
\hline 4 & $\begin{array}{l}\text { CNN-Res-HMM }\{7 \times \operatorname{LWS}(\mathrm{j}: 75 \text { p:1×1 s:1 f:3)+ } \\
3 \times 1024\}\end{array}$ & $7 \mathrm{Cov}+3 \mathrm{Fc}$ & 21.2 & 21.2 & 57 & 191 \\
\hline 5 & 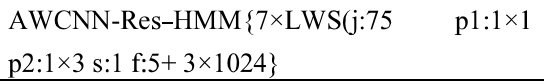 & $7 \mathrm{Cov}+3 \mathrm{Fc}$ & 20.4 & 20.3 & 60 & 410 \\
\hline 6 & $\begin{array}{l}\text { AWCNN-Res-HMM }\{19 \times \text { LWS }(j: 75 \quad \text { p } 1: 1 \times 1 \\
\text { p2:1×3 s: } 1 \text { f:5) }+3 \times 1024\}\end{array}$ & $19 \mathrm{Cov}+3 \mathrm{Fc}$ & 20.2 & 19.8 & 89 & 630 \\
\hline
\end{tabular}

\section{6- References}

[1] ] ج. شيخ زادكان ،م. بـىجن خان، "دادكان كَفتارى زبان

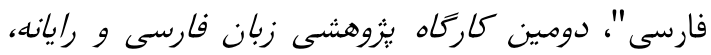

$$
\text { KFV-KGI D.IMAS }
$$

[1] Bi Jan Khan, J. Sheykhzadegan, "Persian speech dataset", in Machine Translation in Persian, 2006, pp. 261-247.

[ץ] ب .باباعلى، "يايه كذارى بسترى نو و كارآمد در حوزه

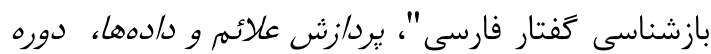

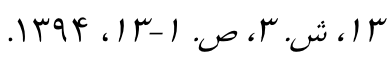

[2] B. BabaAli, "A state-of-the-art and efficient framework for Persian speech recognition", Signal and Data Processing, Vol. 13, No. 3, pp. 1-13, 2015.

[r] س ·ز .سيدصالحى و س.ع. سيدصالحى، "بهبود مدل تفكيك كننده منيفلدهاى غيرخطى بلهنظور بازشناسى جهره با يك تصوير از هر فرد"، يرد/زش علائم و دادهها،

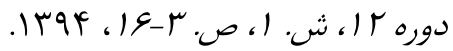

[3] S. Z. Seyyedsalehi, and A. Seyyedsalehi, "Improving the nonlinear manifold separator model to the face recognition by a single image of per person." Signal and Data Processing, Vol. 12, No.1, pp. 3-16, 2015.

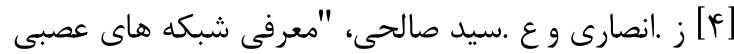
ييمانه اى عميق با ساختار فضايى-زمانى دوزانه جهت

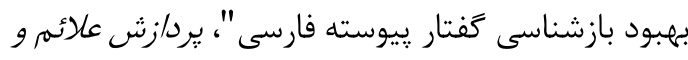

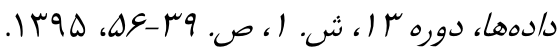

\section{ه- نتيجل}

شبكههاى عصبى عميق، از بهترين ابزارهاى مدل سازى صوت هستند. روشهاى عميق در تركيب با مدل مخفى ماركف تأثير شگرفى در افزايش دقت بازشناسى كفتار دارند. در اين مقاله

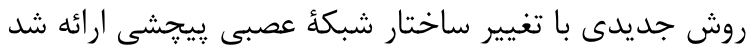

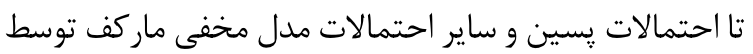
اين روش جديد تخمين زده شود. بازشناسى خودكار كفتار بهعلت تغييرات ويزگى هاى گويندگان و تغييرات زياد سيخنال كفتار، كار بسيار دشوارى است. در اين مقاله با ارائٔ نسخه جديد از شبكة عصبى ييجشى سامانهُ بازشناسى گفتار نسبت

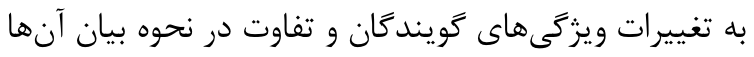
مقاوم مىشود. همجنين در اين مقاله، كفتار با استفاده از

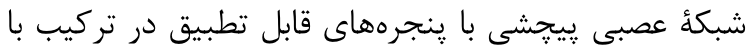

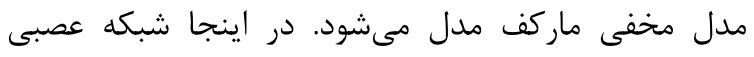

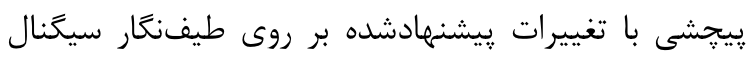
كفتار اعمال شد. تغييرات ييشنهادى منجر شد كه مدل به تغييرات بيانهاى متفاوت يك واج توسط گويندكان مختلف و تغييرات زمانى و فر كانسى جزئى كه در هنگام بيان واج يكسان بلوجود مى آيد، تا حد زيادى مقاوم شود. آزمايشهاى رتى

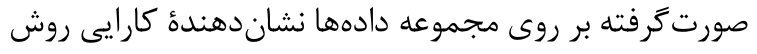
ييشنهادى نسبت به روشهاى ارائهشده قبلى است. نتيجهاى

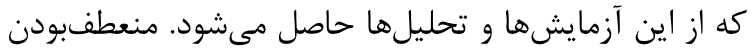

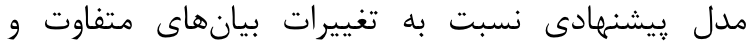

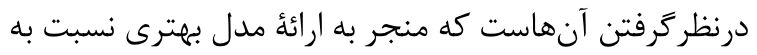
مدلهاى كذشته شد. 
[16] L. Welling, S. Kanthak and H. Ney, "Improved methods for vocal tract normalization," in IEEE International Conference on Acoustics, Speech, and Signal Processing, 1999, vol. 2, pp. 761764.

[17] D. Povey. Discriminative Training for Large Vocabulary Speech Recognition. PhD thesis, Cambridge University, 2003.

[18] S. F. Chen and J. Goodman, "An empirical study of smoothing techniques for language modeling," in Proceedings of the 34th annual meeting on Association for Computational Linguistics, 1996, pp. 310-318.

[19] G. E. Dahl, D. Yu, L. Deng and A. Acero, "Context-dependent pre-trained deep neural networks for large-vocabulary speech recognition," IEEE Transactions on Audio, Speech and Language Processing, vol. 20, no. 1, pp. 30-42, 2012.

[20] G. Hinton, L. Deng, D. Yu, G. E. Dahl, A Mohamed, N. Jaitly, A. Senior, V. Vanhoucke, P. Nguyen, T. N. Sainath, and B. Kingsbury, "Deep Neural Networks for Acoustic Modeling in Speech Recognition: The Shared Views of Four Research Groups," IEEE Signal Processing Magazine, vol. 29, no. 6, pp. 82-97, 2012

[21] A. R. Mohamed, G. Hinton and G. Penn, "Understanding how deep belief networks perform acoustic modelling," in IEEE International Conference on Acoustics, Speech and Signal Processing, 2012, pp. 4273-4276.

[22] R. Salakhutdinov and G. Hinton, "An Efficient Learning Procedure for Deep Boltzmann Machines," Neural Computation, vol. 24, no. 8, pp. 1967-2006, 2012.

[23] R. Salakhutdinov, "Learning deep generative models," PHD thesis, Toronto, Ont., Canada, 2009.

[24] G. E. Hinton, "Training products of experts by minimizing contrastive divergence," Neural Computation, vol. 14, no. 8, pp. 1771-1800, 2002.

[25] G. E. Hinton, S. Osindero, and Y. W. Teh, "A fast learning algorithm for deep belief nets," Neural computation, vol. 18, no. 7, pp. 1527-1554, 2006.

[26] P. Ramesh and J. G. Wilpon, "Modeling state durations in hidden Markov models for automatic speech recognition," in IEEE International Conference on Acoustics, Speech, and Signal Processing, 1992, vol. 1, pp. 381-384.

[27] P. N. Justine T. Kao, Geoffrey Zweig, "Discriminative duration modeling for speech recognition with segmental conditional random fields," in ICASSP, 2011. PP. 4476-4479.
[4] Z. Ansari, and A. Seyyedsalehi, "Deep Modular Neural Networks with Double Spatio-temporal Association Structure for Persian Continuous Speech Recognition." Signal and Data Processing, Vol. 13, No.1, pp. 39-56, 2016.

$$
\begin{aligned}
& \text { [ه] س .ز .سيدصالحى و س .ع .سيدصالحى، "روش پِيش } \\
& \text { تعليم سريع بر مبناى كمينهسازى خطا براى همخرائى نى ني } \\
& \text { يادَيرى شبكههاى عصبى با ساختار عميق"، يرد/زش }
\end{aligned}
$$

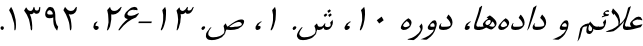

[5] S. Z. Seyyedsalehi, and A. Seyyedsalehi, "A new fast pre training method for training of deep neural network." Signal and Data Processing, Vol. 10, No.1, pp. 13-26, 2013.

[6] Y. Hifny and S. Renals, "Speech recognition using augmented conditional random fields," IEEE Transactions on Audio, Speech and Language Processing, vol. 17, no. 2, pp. 354-365, 2009.

[7] K. H. Davis, R. Biddulph, and S. Balashek, "Automatic Recognition of Spoken Digits," The Journal of the Acoustical Society of America, vol. 24, no. 6, p. 637-642, 1952.

[8] L. Rabiner and B. Juang, Fundamentals of Speech Recognition: Prentice Hall, vol. 22. 1993.

[9] R. P. Lippmann, "Speech recognition by machines and humans," Speech Communication, vol. 22, no. 7, pp. 1-15, 1997.

[10] O. Scharenborg, "Reaching over the gap: A review of efforts to link human and automatic speech recognition research," Speech Communication, vol. 49, no. 5, pp. 336-347, 2007.

[11] M. Ostendorf, "Moving Beyond the "Beads-on-aString' Model of Speech," in IEEE Automatic Speech Recognition and Understanding Workshop, 1999, pp. 79-83.

[12] H. Bourlard, H. Hermansky, and N. Morgan, "Towards increasing speech recognition error rates," Speech Communication, vol. 18, no. 3, pp. 205-231, 1996.

[13] N. Morgan, Q. Zhu, and A. Stolcke, "Pushing the envelope-aside," Signal Processing Magazine, vol. 22 , no. 5, pp. 81-88, 2005.

[14] C. J. Leggetter and P. C. Woodland, "Maximum likelihood linear regression for speaker adaptation of continuous density hidden Markov models," Computer Speech \& Language, vol. 9, no. 2, pp. 171-185, 1995.

[15] L. Lee and R. C. Rose, "Speaker normalization using efficient frequency warping procedures," in IEEE International Conference on Acoustics, Speech, and Signal Processing, 1996, vol. 1, pp. 356-1996. 
Transactions on Speech and Audio Processing, vol. 22, no. 10, pp. 1533-1545, 2014.

[40] G. Heigold, "A log-linear discriminative modeling framework for speech recognition," $\mathrm{PhD}$ dissertation, Aachen, Germany, 2010.

[41] M. Russell and A. Cook, "Experimental evaluation of duration modelling techniques for automatic speech recognition," in IEEE International Conference on Acoustics, Speech, and Signal Processing, 1987, vol. 12, pp. 2376-2379.

[42] H. Lee and H. Kwon, "Going Deeper with Contextual CNN for Hyperspectral Image Classification," IEEE Transactions on Image Processing, vol. 26, no. 10, pp. 4843-4855, 2017.

[43] C. Dong, C. C. Loy, K. He, and X. Tang, "Image Super-Resolution Using Deep Convolutional Networks," IEEE Transactions on Pattern Analysis and Machine Intelligence, vol. 38, no. 2, pp. 295-307, 2016.

[44] K. He, X. Zhang, S. Ren, and J. Sun, "Deep Residual Learning for Image Recognition," in IEEE Conference on Computer Vision and Pattern Recognition (CVPR), 2016, pp. 770-778.

[45] A. Graves, A. Mohamed, and G. Hinton, "Speech Recognition with Deep Recurrent Neural Networks," in Acoustics, Speech and Signal Processing (ICASSP), 2013, no. 3, pp. 66456649.

[46] Y. Miao, M. Gowayyed, and F. Metze, "EESEN: End-to-end speech recognition using deep RNN models and WFST-based decoding," in IEEE Workshop on Automatic Speech Recognition and Understanding, ASRU 2015 - Proceedings, 2016, pp. 167-174.

[47] W. Song and J. Cai, "End-to-End Deep Neural Network for Automatic Speech Recognition," CS224d: Deep Learning for Natural Language Processing, pp. 1-8, 2015.

[48] S. Kapadia, V. Valtchev and S. J. Young, "MMI training for continuous phoneme recognition on the TIMIT database," in IEEE International Conference on Acoustics, Speech, and Signal Processing, 1993, vol. 2, pp. 491-494.

[49] M. Bijankhan, J. Sheikhzadegan, and M. R. Roohani, Y. Samareh, "FARSDAT- the speech database of farsi spoken language," in proceedings Australian conference on speech science and technology, 1994, vol. 2, pp. 826830.

[50] B. H. Juang, W. Chou, and C. H. Lee, "Minimum classification error rate methods for speech recognition," IEEE Transactions on Speech and Audio Processing, vol. 5, no. 3, pp. 257-265, 1997.

[51] E. McDermott, T. J. Hazen, J. Roux, A. Nakamura and S. Katagiri, "Discriminative
[28] S. Z. Yu, "Hidden semi-Markov models," Artificial Intelligence, vol. 174, no. 2. pp. 215243, 2010.

[29] S. J. Rennie, P. Fousek, and P. L. Dognin, "factorial hidden restricted boltzmann machines for noise robust speech recognition," in IEEE International Conference on Acoustics, Speech and Signal Processing, 2012, pp. 4297-4300.

[30] J. Huang and B. Kingsbury, “Audio-visual deep learning for noise robust speech recognition," in IEEE International Conference on Acoustics, Speech and Signal Processing, 2013, pp. 75967599.

[31] A. Maas and Q. Le, "Recurrent Neural Networks for Noise Reduction in Robust ASR.," in Interspeech, 2012, pp. 3-6.

[32] H. Bourlard and N. Morgan, "Continuous speech recognition by connectionist statistical methods," IEEE Transactions on Neural Networks, vol. 4, no. 6, pp. 893-909, 1993.

[33] A. J. Robinson, G. D. Cook, D. P. W. Ellis, E. Fosler-Lussier, S. J. Renals, and D. A. G. Williams, "Connectionist speech recognition of Broadcast News," Speech Communication, vol. 37, no. 1-2, pp. 27-45, 2002.

[34] Y. H. Sung and D. Jurafsky, "Hidden conditional random fields for phone recognition," in IEEE Workshop on Automatic Speech Recognition and Understanding, 2009, pp. 107-112.

[35] T. N. Sainath, A. R. Mohamed, B. Kingsbury and B. Ramabhadran, "Deep convolutional neural networks for LVCSR," in IEEE International Conference on Acoustics, Speech and Signal Processing, 2013, pp. 8614-8618.

[36] T. N. Sainath, B. Kingsbury, G. Saon, H. Soltau, A.-R. Mohamed, G. Dahl, and B. Ramabhadran, "Deep Convolutional Neural Networks for Large-scale Speech Tasks.," Neural networks, vol. 64, pp. 39-48, Sep. 2014.

[37] T. N. Sainath, B. Kingsbury, H. Soltau and B. Ramabhadran, "Optimization techniques to improve training speed of deep neural networks for large speech tasks," IEEE Transactions on Audio, Speech and Language Processing, vol. 21, no. 11, pp. 2267-2276, 2013.

[38] H. Lee, R. Grosse, R. Ranganath, and A. Y. Ng, "Convolutional deep belief networks for scalable unsupervised learning of hierarchical representtations," in Proceedings of the 26th Annual International Conference on Machine Learning, 2009, vol. 2008, pp. 1-8.

[39] O. Abdel-Hamid, A. Mohamed, H. Jiang, L. Deng, G. Penn, and D. Yu, "Convolutional neural networks for speech recognition," IEEE 
Training for Large-Vocabulary Speech Recognition Using Minimum Classification Error," IEEE Transactions on Audio, Speech and Language Processing, vol. 15, no. 1, pp. 203223, 2007.

[52] F. Sha and L. Saul, "Large Margin Gaussian Mixture Modeling for Phonetic Classification and Recognition," in IEEE International Conference on Acoustics Speech and Signal Processing Proceedings, 2006, vol. 1, pp. 265268.

[53] G. Zweig, P. Nguyen, D. Van Compernolle, K. Demuynck, L. Atlas, P. Clark, G. Sell, M. Wang, F. Sha, H. Hermansky, D. Karakos, A. Jansen, S. Thomas, S. Bowman and J. Kao, "Speech recognition with segmental conditional random fields," in IEEE International Conference on Acoustics, Speech and Signal Processing, 2011, pp. 5044-5047.

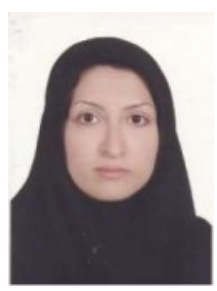

تكتم ذوقى تحصيلات خود را در مقطع

كارشناسى ارشد رشته مهندسى كامييوتر

(هوش مصنوعى) در دانشعاه شيراز

(هNAN)

دانشجوى مقطع دكتراى كامييوتر (هوش

مصنوعى) در دانشخاه صنعتى امير كبير است. موضوعات مورد

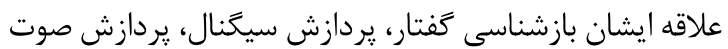
و يردازش تصوير است.

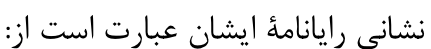

tzoughi@aut.ac.ir

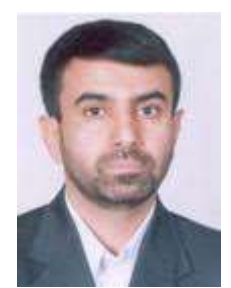

محمدمهردى همايونيور تحصيلات خود

را در مقطع كارشناسى در رشته برق

(الكترونيك) در دانشخاه صنعتى اميركبير

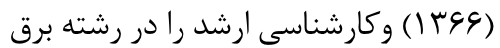

(مخابرات) در دانشخاه خواجه نصيرالدين

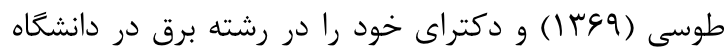

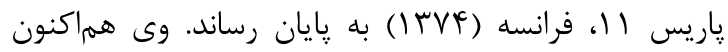

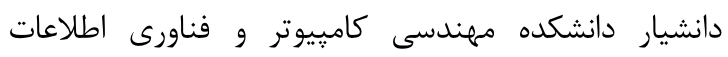
دانشعاه اميركبير است. موضوعات مورد علاقئ ايشان يردازش

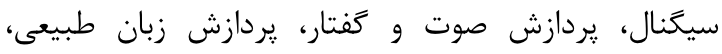
يادگيرى ماشين و جندرسانهاى است. نشانى رايانامةٔ ايشان عبارت است ازئ homayoun@aut.ac.ir 
